$44 \mid 2018$

Les valorisations territoriales et touristiques du street art

\title{
Couvrez ce béton que je ne saurais voir...
}

La valorisation territoriale et touristique des peintures murales de la marina d'Horta (Açores)

\section{Louis Marrou}

\section{OpenEdition}

\section{Journals}

Édition électronique

URL : https://journals.openedition.org/echogeo/15845

DOI : $10.4000 /$ echogeo. 15845

ISSN : 1963-1197

Éditeur

Pôle de recherche pour l'organisation et la diffusion de l'information géographique (CNRS UMR 8586)

Référence électronique

Louis Marrou, "Couvrez ce béton que je ne saurais voir... », EchoGéo [En ligne], 44 | 2018, mis en ligne le 31 juillet 2018, consulté le 31 juillet 2021. URL : http://journals.openedition.org/echogeo/15845 :

DOI : https://doi.org/10.4000/echogeo.15845

Ce document a été généré automatiquement le 31 juillet 2021.

EchoGéo est mis à disposition selon les termes de la licence Creative Commons Attribution - Pas d'Utilisation Commerciale - Pas de Modification 4.0 International (CC BY-NC-ND) 


\section{Couvrez ce béton que je ne saurais voir.}

La valorisation territoriale et touristique des peintures murales de la marina d'Horta (Açores)

\section{Louis Marrou}

1 Une étoile au guide Vert Michelin «Intéressant " pour une marina moderne, celle d'Horta, n'est pas quelque chose de fréquent. L'île de Faial ne compte que trois autres sites «remarquables» dans ce même guide: le volcan du Capelinhos (trois étoiles: "Vaut le détour »), le Monte da Guia et la Caldeira (deux étoiles : " Mérite un détour »). Si des quais et des jetées de béton peuvent avoir un intérêt pour le plaisancier, on s'étonne de voir cette infrastructure plébiscitée pour le touriste découvrant cette île, l'une des neuf de l'archipel portugais des Açores. On le comprend mieux en lisant le commentaire qui accompagne la distinction: "C'est le rendez-vous des marins qui effectuent la traversée de l'Atlantique. Elle est devenue une galerie d'art en plein air où chaque équipage laisse sa trace iconographique (le contraire porte malheur... disent les superstitieux). » 
Illustration 1 - Les peintures de la marina d'Horta et l'île de Pico en arrière-plan

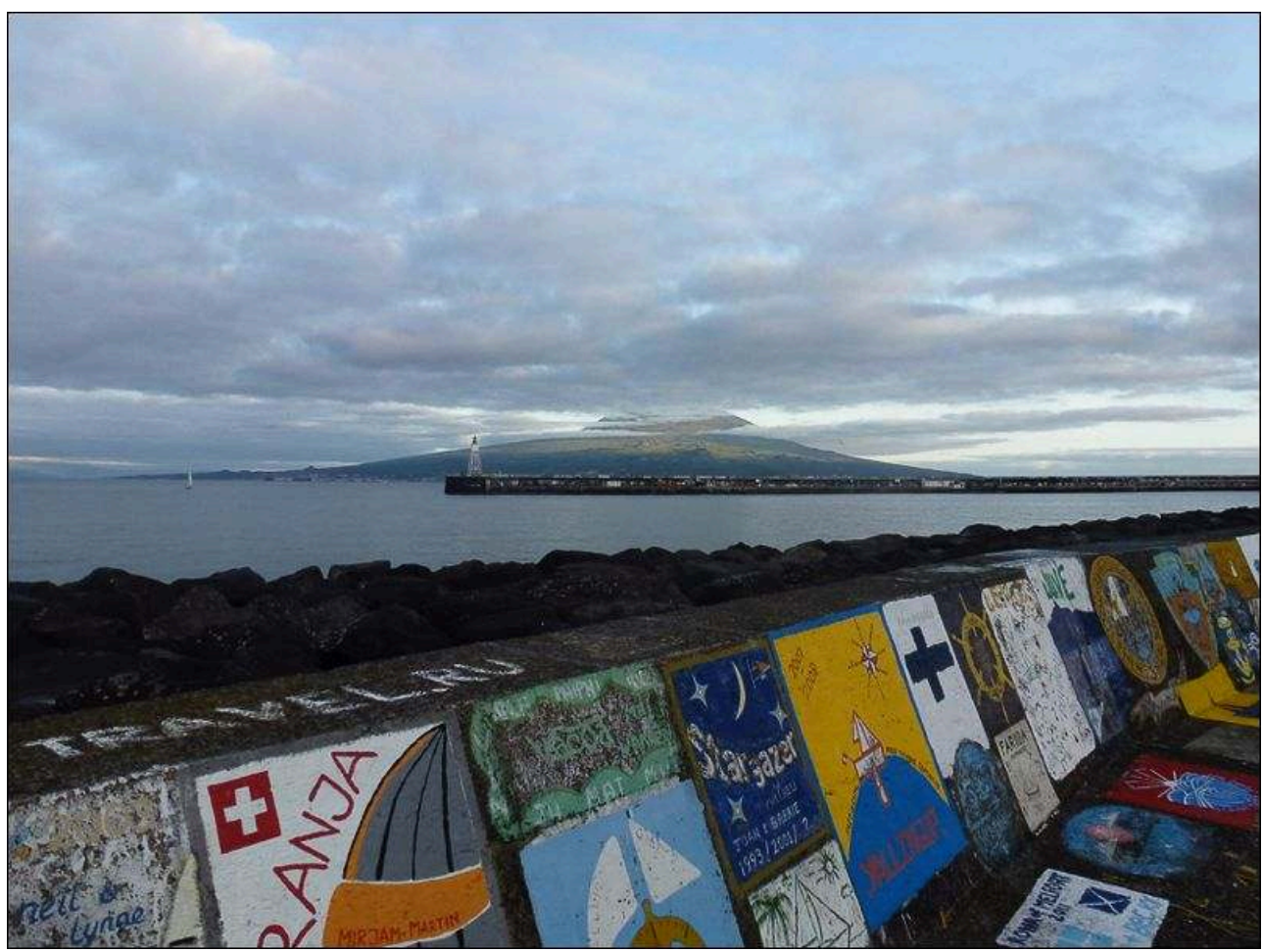

Auteur : L. Marrou, 2013

2 La marina d'Horta a fêté ses 30 ans en 2016 et s'avère unique au monde par son décor. C'est d'abord la présence à l'horizon, du côté du soleil levant, du volcan Pico et ses 2351 mètres d'altitude, sur l'île homonyme (illustration 1). C'est aussi un incroyable enchevêtrement de milliers de peintures murales de petites tailles qui recouvrent la quasi-totalité des quais et murs d'une marina abritant environ 300 bateaux. L'ensemble offre ainsi une myriade de représentations qui est devenue aussi attractive que les églises baroques de cette petite ville née au $\mathrm{XV}^{\mathrm{e}}$ siècle, à l'aube des «Grandes Découvertes ».

Le cas de cette marina interpelle pour plusieurs raisons. Sommes-nous face à une version insulaire et portuaire du street art ou pour le moins du " quai-art », ce que des Anglais croisés lors de nos enquêtes sur les jetées traitent non sans humour de «PierArt $»^{1}$ (l'art du pirate ?) ? Comment sont apparues dans le port, et dans la ville, ces productions graphiques? Ces peintures sont-elles regardées uniquement par les plaisanciers, où sont-elles intégrées dans un circuit touristique plus large, à l'échelle de la cité, de l'île ou de l'archipel ? Certaines similitudes avec le street art semblent fortes si l'on prend celui-ci comme «l'ensemble des produits artistiques réalisés dans les espaces publics» (Bottani, 2016, p. 10): public, éphémère, multiple par ses formes. D'autres caractéristiques de ces représentations militent pour une forme bien spécifique : concentration en un seul lieu de milliers de peintures, pas de caractère illégal de la pratique, des « artistes » qui sont le plus souvent de passage, en escale. Les « peintures » de la marina d'Horta attirent l'œil, ne laissent pas indifférent et circulent sur les réseaux sociaux au gré des milliers de photographies prises chaque année. On peut reprendre l'affirmation de J. Catz : « Le street art ne cherche pas à se fondre dans le 
paysage, au contraire, il poursuit un but ultime : se montrer» (Catz, 2013, p. 16,). Mirons!

\section{La marina la plus colorée du monde}

4 Si l'on en croit le site Internet de promotion du tourisme au Portugal ${ }^{2}$, Horta est la marina la plus colorée du monde. «À Faial, la visite de la marina de Horta s'impose, en raison de l'animation des yachts qui y jettent l'ancre et de la grande exposition à ciel ouvert de peintures, réalisées spontanément par tous les marins qui la visitent ». La coloration n'est pas ici ni liée à l'exotisme, ni à un climat tropical, mais elle vient de la gamme infinie des couleurs des pots de peinture que l'on peut trouver à bord d'une embarcation ou chez les accastilleurs de tous les ports du monde.

Il n'existe que très peu de travaux scientifiques sur cette tradition maritime qui voit donc les équipages de passage orner les murs de la marina d'une peinture évoquant leur bateau, leur trajet ou l'équipage. Une chose est sûre, la tradition est antérieure à la création de la marina en 1986 et nous oblige à plonger dans l'histoire de la ville et de son port.

\section{Le surgissement de la marina}

6 Le port d'Horta dispose d'un grand môle depuis le milieu du XIX ${ }^{\mathrm{e}}$ siècle (Barreira, 1995). Jusqu'à la construction de la marina, ce long quai accueille dans un joyeux désordre les navires de commerce, les bateaux de pêche, les embarcations militaires et les quelques voiliers de plaisance qui cinglent au gré des vents entre les côtes américaines et européennes. C'est un quai de grande hauteur qui met à l'abri le port des principales houles. Il est fait d'énormes blocs de basalte et d'un appareillage de béton et de ciment. La tonalité générale est sombre. C'est sur les blocs de lave que les premières inscriptions surgissent à la fin des années 1950 . On pense que ce sont des équipages des bateaux de pêche étrangers à l'archipel qui les premiers ont laissé une marque. L'inscription se contente le plus souvent du numéro d'immatriculation de l'embarcation ou de son nom. Dans les années 1960 et 1970, l'habitude perdure (illustration 2). Toute embarcation a à son bord la peinture nécessaire au bon entretien du navire et il est donc facile de «barbouiller » les pierres inégales du « Grand Mur de Faial » comme le surnomme Reese Palley ${ }^{3}$. Le môle ne fait pas partie de la ville. Il ferme le port, au loin. 
Illustration 2 - Les premières peintures sur le mur de la grande digue du port d'Horta

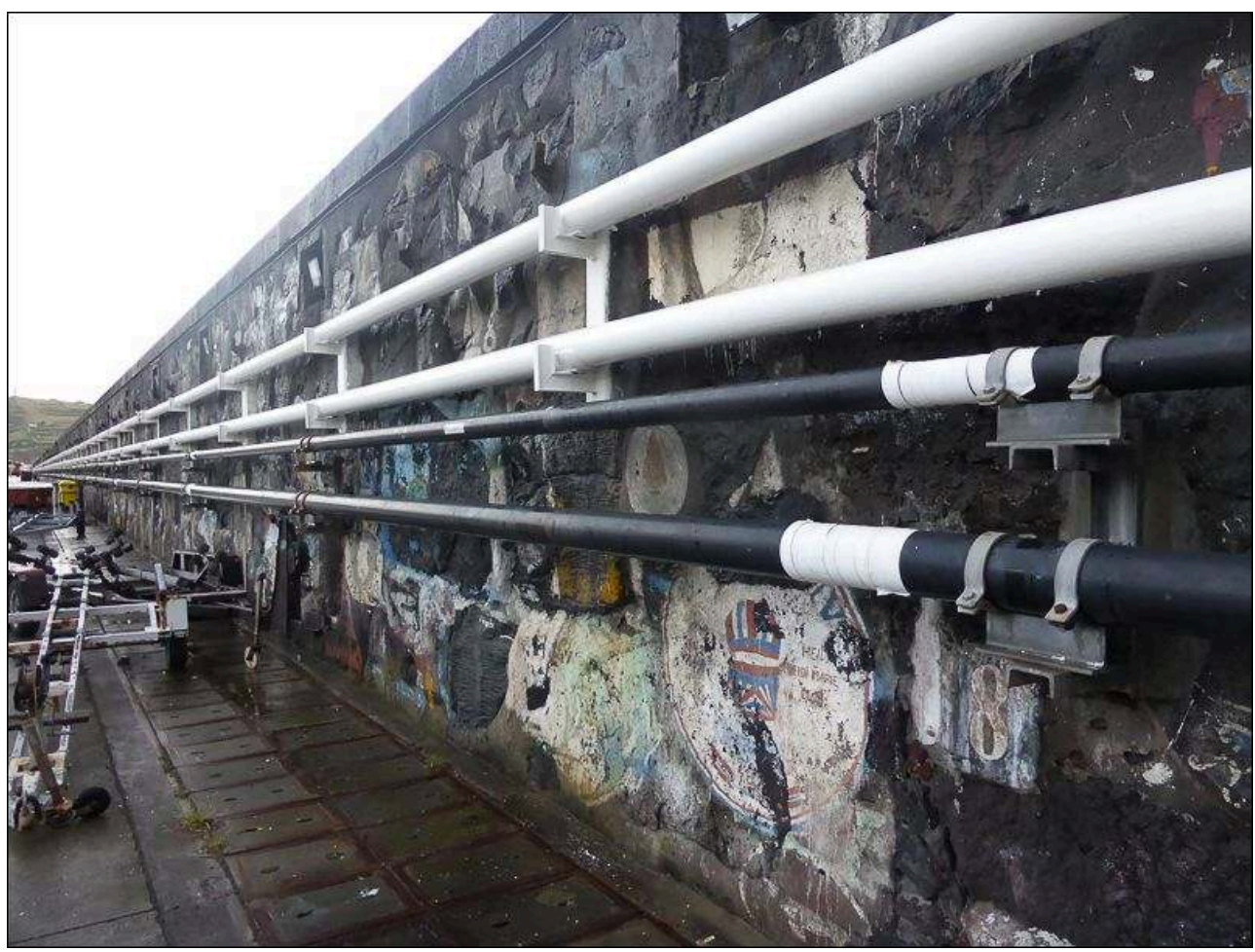

Auteur : L. Marrou, 2017

7 Au début des années 1980, l'idée surgit de construire une marina à Horta (Demarthon, 2003). La plaisance se développe à toute vitesse et le nombre de plaisanciers traversant l'océan Atlantique croit fortement. Ils sont désormais plusieurs centaines par an. Ils forment une partie des " touristes » d'une île qui est plongée dans un certain marasme économique. La bigarrure historique de l'île de Faial, l'île des câbles transatlantiques, et sa position centrale dans l'archipel lui donnent l'avantage sur d'autres sites possibles. C'est à l'époque un pari. La grève est donc aménagée sous l'égide de l'Autorité Portuaire de l'île de Faial. Celle-ci est au contact de la ville, au pied de la forteresse qui a longtemps protégé l'entrée de la baie.

8 En 1986, l'ouverture de la marina est une fantastique nouveauté urbaine qui va modifier les équilibres de cette ville de quelques milliers d'habitants. La marina est au pied de la colline où est installé l'observatoire du Prince de Monaco, et jouxte le quartier de Porto Pim qui regroupe les familles de pêcheurs (illustration 3). À l'autre extrémité de la baie se trouve l'essentiel du centre urbain. La marina est alors perçue comme une excroissance, une verrue dans la ville. Elle est en périphérie. C'est assurément un monde différent, celui des "voileux». Ils sont acceptés dans la ville, mais à part. Ce sont des aventuriers. 


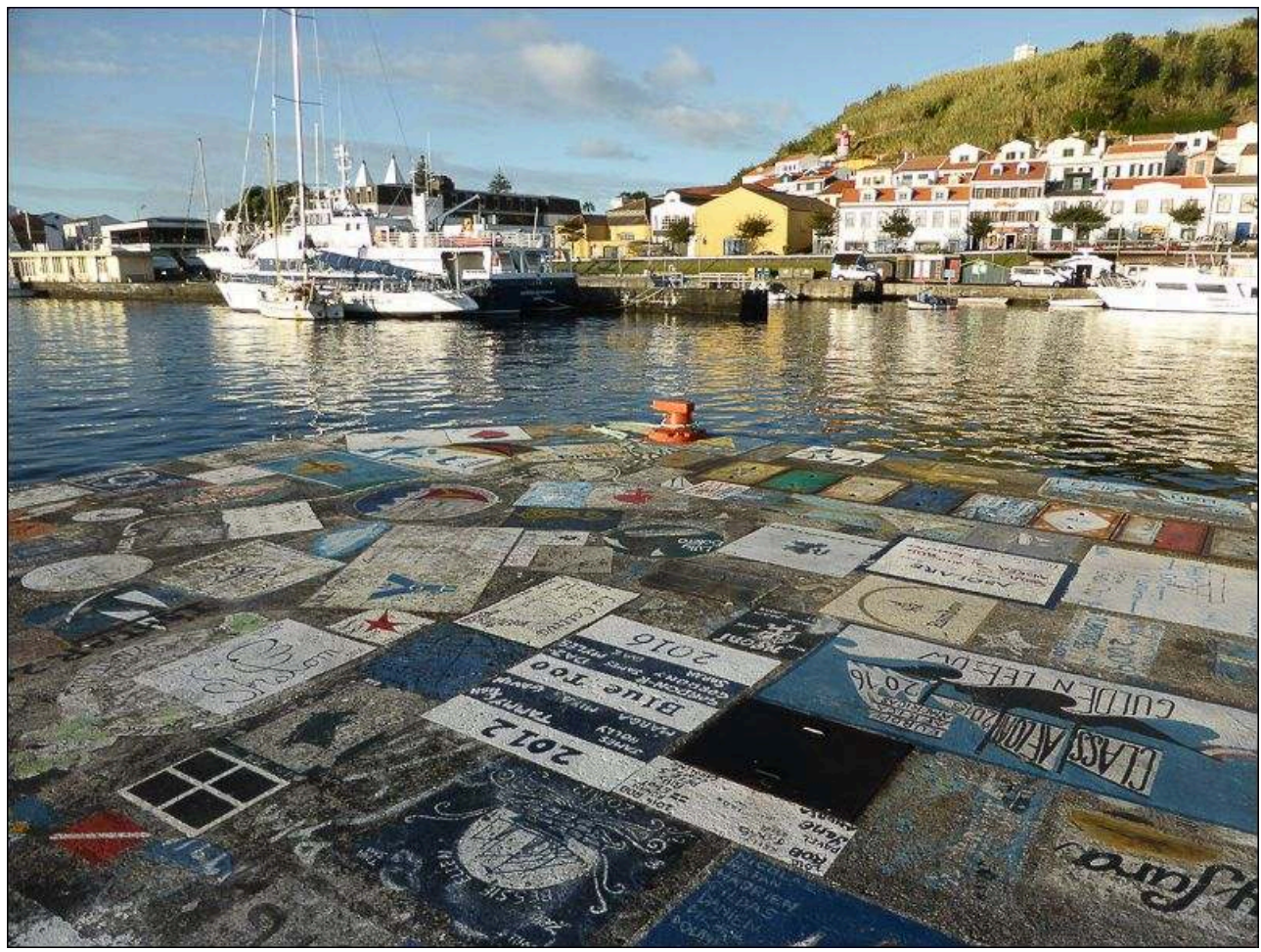

En arrière-plan la colline qui porte l'observatoire météorologique du Prince de Monaco en haut à droite. Auteur: L. Marrou, 2016

On peut voir le surgissement de cet équipement comme l'expression d'une forme de requalification urbaine à l'instar du remodelage de nombreux quartiers où fleurissent les représentations picturales urbaines (Bottani, 2016, p. 54). La marina est construite devant le vieux fort de la ville, une portion de la façade urbaine relativement délaissée. Comme dans l'Est parisien et à Pantin, on peut faire l'hypothèse «que le street art participe à la réinvention volontariste d'une identité territoriale qui met en avant la créativité » (Blanchard, 2017, p. 2).

L'architecture, moderne, tranche avec le caractère traditionnel de la ville d'Horta. Le béton y est roi, droit, lisse, clair. Il jure avec la rugosité des encoignures de basalte des édifices ou les aspérités des petits blocs de pierre qui font les trottoirs. C'est le seul endroit de la ville où l'on peut accéder au bord de mer facilement. Le reste de la baie est engoncé dans une immense digue derrière laquelle la ville se sent à l'abri mais qui la coupe en quelque sorte de l'océan.

11 La marina a petit à petit été " absorbée ", digérée par la ville. Elle en est devenue l'un des pôles majeurs d'activité. De nouveaux établissements sont venus se greffer. Les activités de transport et de tourisme y sont les mieux représentées. Les hôtels et les restaurants sont nombreux et le développement de l'observation des cétacés et les sorties en mer pour de la pêche sportive ont démultiplié l'offre touristique.

\section{Les nouveaux ex-votos?}

12 Les «peintures $»^{4}$ de la marina d'Horta couvrent plusieurs milliers de $\mathrm{m}^{2}$ (quai, parapet...) et courent le long de plus de 3 kilomètres de quai. Un comptage effectué par 
nos soins au printemps 2014 évalue à environ 13700 le nombre de peintures. Le chiffre est approximatif car les peintures s'effacent au fil du temps et il devient parfois difficile de les distinguer. Par ailleurs les différents supports doivent être regardés comme autant de palimpsestes. Il n'est pas rare qu'une peinture en recouvre une plus ancienne, délavée, en particulier dans certains emplacements de la marina. Par l'amoncellement des signes, les supports de la marina en évoquent certains emblématiques du street art, comme le mur de Berlin ou les trains et métros de NewYork (Dogheria, 2016).

13 Au fil des années, des localisations se distinguent. Elles sont plus prisées que d'autres. On s'y serre et les places libres sont rares. C'est le cas du quai où appontent les bateaux les plus prestigieux, navire-école ou trois mats par exemples au pied de la colline de l'observatoire et en face du Peter Café Sport, le café des navigateurs à Horta, emblématique depuis plus d'un demi-siècle (illustration 4). À l'autre bout de la marina, le parapet qui la sépare des eaux du port de commerce est aussi considéré comme une pièce de choix, une cimaise idéale avec en arrière-plan pour les peintures le cône du volcan Pico.

Illustration 4 - Des dizaines de représentations dans des styles très différents

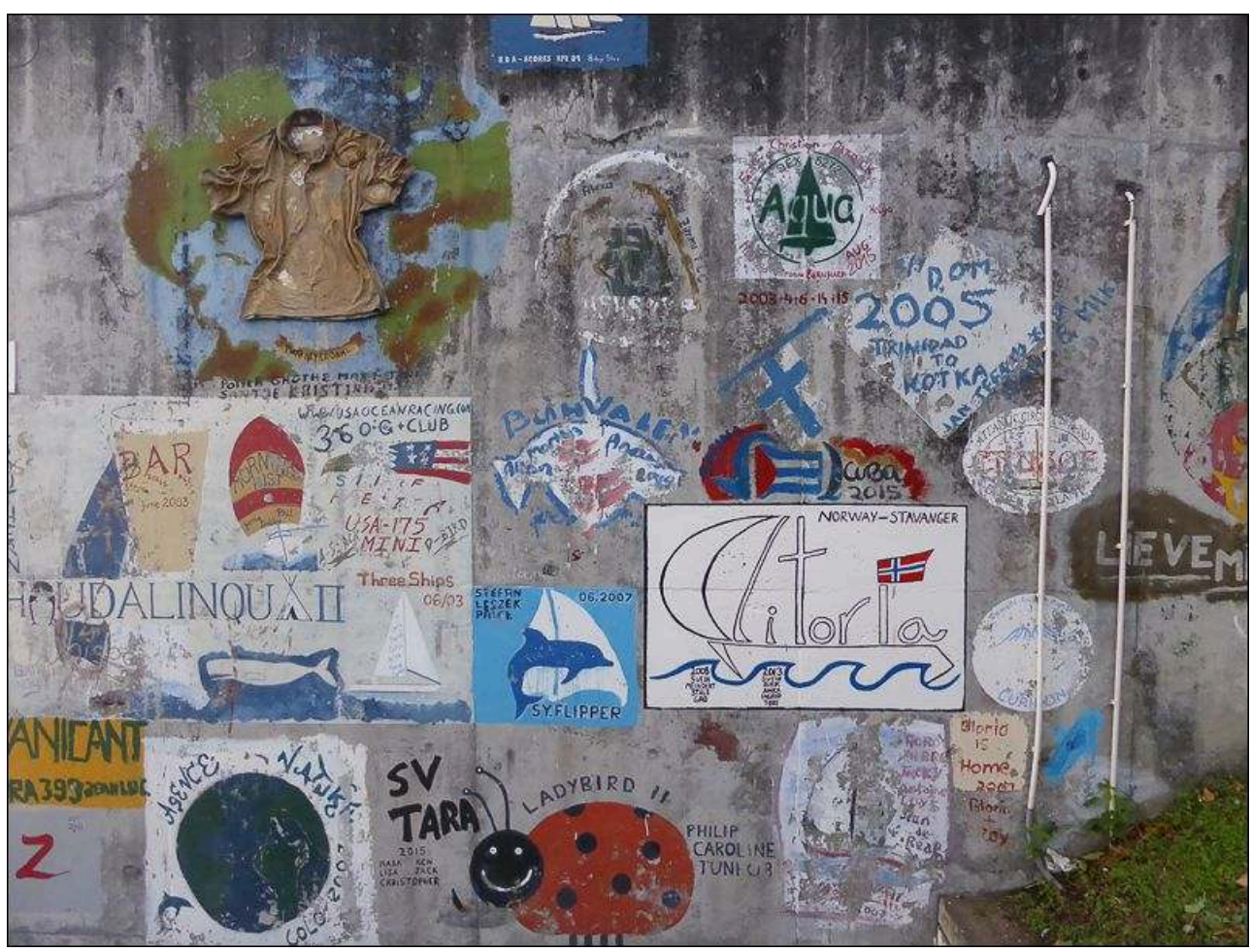

Auteur : L. Marrou, 2016

À l'inverse certaines zones semblent délaissées (illustration 5). Il s'agit globalement des espaces de roulement, des quais qui sont empruntés par les voitures qui viennent desservir les embarcations. La dégradation des peintures y est assurément plus rapide. Celle-ci dépend aussi grandement de la qualité des dites peintures et des techniques utilisées. Il n'est pas rare de voir certaines représentations montrant des détériorations importantes au bout d'une année seulement. D'autres semblent traverser le temps. Certaines ont plus de vingt ans. Par contre, il est difficile de retrouver trace des 
premières peintures datant de 1986. Elles nous sont connues par des cartes postales qui ont été faites l'année de l'inauguration de la marina.

Illustration 5 - Carte des peintures de la marina d'Horta

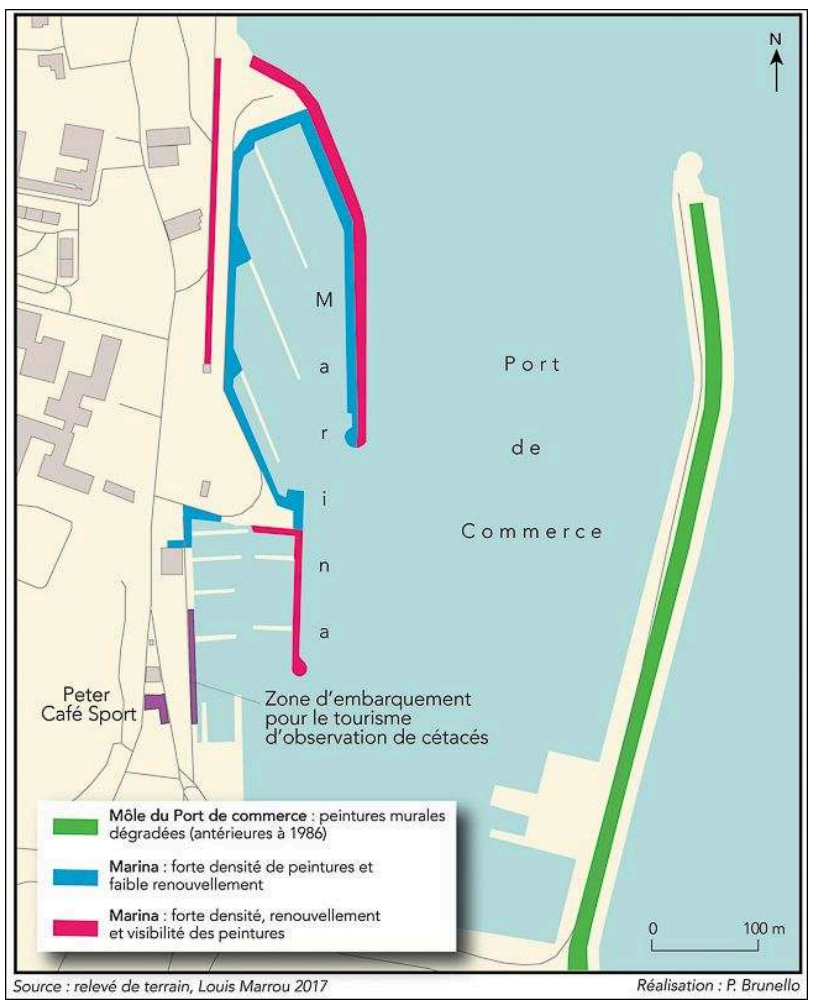

Auteur : P. Brunello

Aucun registre n'existe sur les peintures de la marina mais les recensements que nous menons systématiquement depuis maintenant plus d'une dizaine d'années révèlent deux choses. D'une part on peut estimer à un équipage d'embarcation sur deux, ceux qui se plient à la tradition. Les enquêtes menées au port permettent de comprendre ce qui peut apparaitre comme une forte volatilité dans les pratiques par rapport à la « légende » et aux on-dit ${ }^{5}$. De nombreux équipages ne font pas à chaque passage une nouvelle peinture. Ils se contentent souvent de venir rajouter sur la précédente, la nouvelle date de leur passage (illustration 6). Certaines peintures d'un même bateau peuvent ainsi relater jusqu'à une dizaine de traversées transatlantiques. Les équipages qui ne laissent pas de trace iconographique évoquent le manque de temps, le peu d'appétence pour la pratique du dessin, le caractère désuet de la pratique ou le choix d'autres supports de communication comme les blogs en particulier. 
Illustration 6 - Peinture de l'équipage du trois mats suédois Gunilla

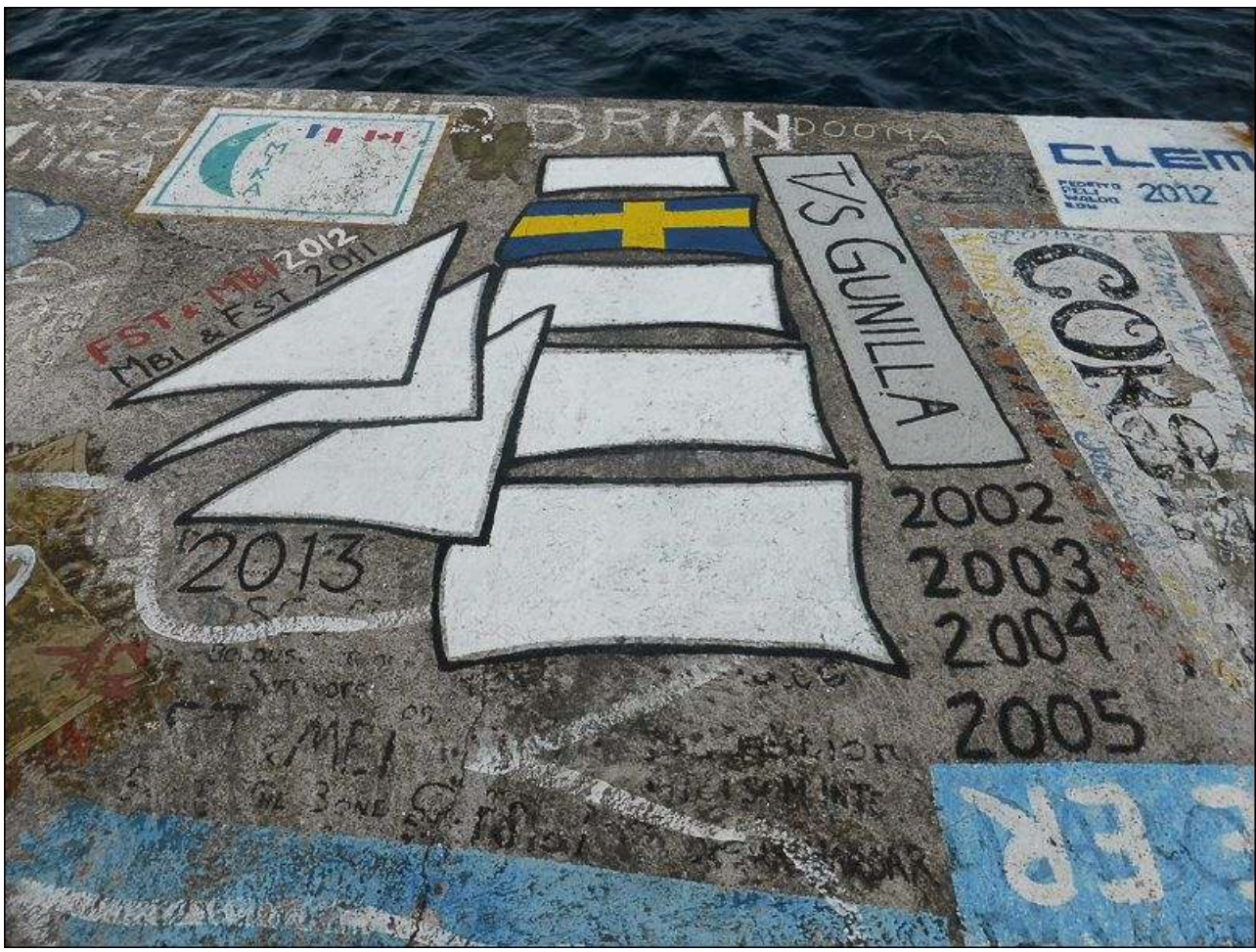

Navire école qui passe régulièrement par Horta comme en témoignent les années visibles sur la peinture.

Auteur : L. Marrou, 2013

Pour ceux qui peignent, beaucoup le font au nom de la tradition et pour montrer leur appartenance à la communauté des gens de mer, au monde des marins. C'est en cela que la pratique se rapproche de celle de l'ex-voto même si là il ne s'agit pas spécifiquement de l'expression d'un vœu. Toucher Horta après 10 ou 15 jours de mer reste toujours un moment magique, celui où l'on retrouve la terre ferme, les amis et un mode de vie réglé par autre chose que la bonne marche de l'embarcation. Ils sont de la mer. Ils en sont fiers. Ces plaisanciers sont souvent des marins confirmés, plus proches de la soixantaine que de la vingtaine d'années. Ils abordent une terre, une ville qui est soit une escale, soit un terminus, avec le développement de la pratique des demitransats. Depuis le début du XXI ${ }^{e}$ siècle, la plaisance dans l'océan Atlantique a beaucoup évolué avec l'irruption des routeurs, l'amélioration des prévisions météorologiques maritimes, des pilotes automatiques, des systèmes électroniques de navigation, des G.P.S. ${ }^{6}$, A.I.S. ${ }^{7}$ et autres radars. Une nouvelle génération de navigateurs, plus jeune court l'océan. Les traditions maritimes évoluent, le statut et le style des peintures aussi.

\section{L'art est au port}

17 Pour de nombreux observateurs, les peintures murales de la marina d'Horta forment un immense musée à ciel ouvert. Notre propos est d'interroger cet ensemble de représentations comme participant d'un mouvement d'expression artistique en ville. Cela pose la question du statut urbain de la marina, de sa place dans la ville mais aussi 
du statut des peintures elles-mêmes. Doivent-elles être prise individuellement, où fautil les voir comme un ensemble, un tout, au regard de la ville açorienne?

Les caractéristiques de ces représentations les rapprochent de façon claire de certaines des formes plus classiques du street art. Elles sont indubitablement visuelles, colorées, visibles. Elles se déploient dans l'espace public et s'arrêtent dès que commencent les pontons et les panes qui sont réservées à l'utilisation exclusive des navigateurs. C'est un art spontané, non encadré par les autorités portuaires qui portent cependant un regard bienveillant sur ces pratiques. En 1986, le gestionnaire de la marina a laissé faire les premiers navigateurs adeptes du pinceau. Au fil des années, l'habitude s'est ancrée. Elle est discrètement encouragée. La capitainerie peut mettre à disposition un kit de peinture avec quelques pots. La multiplication des voiliers en matières composites restreint fortement l'usage de la peinture à bord. Il n'y a pas à proprement parler d'institutionnalisation de la pratique. Enfin, c'est une expression éphémère. Il n'y a pas à notre connaissance de préservation ou de politique de conservation des peintures.

L'entretien de la marina et sa modernisation font fi de la présence des peintures. Au fil des ans et des travaux, au gré des conversations avec le personnel de la marina, il apparaît comme évident que les quais colorés sont assimilés à des quais classiques. L'installation de grosses poubelles de tri à la fin des années 2000 a ainsi fait disparaître de nombreuses peintures tout comme certains travaux de câblage qui entrainent de grandes tranchées sur les quais et les représentations. Ces travaux d'aménagement permettent même parfois un renouvellement plus rapide des peintures (illustration 7). $\mathrm{Au}$ printemps 2017, plusieurs dizaines de $\mathrm{m}^{2}$ de béton neuf ont ainsi été offerts aux mains des navigateurs à la suite de travaux de voierie. L'espace a attiré un grand nombre de plaisanciers qui sont venus y réaliser leurs œuvres. En moins de 6 mois, il n'y avait plus un centimètre de béton frais dans un secteur un peu sanctuarisé, où le renouvellement pictural est souvent lent. 
Illustration 7 - Renouvellement des « supports » pour les peintures à la suite de travaux sur les quais de la marina en 2017

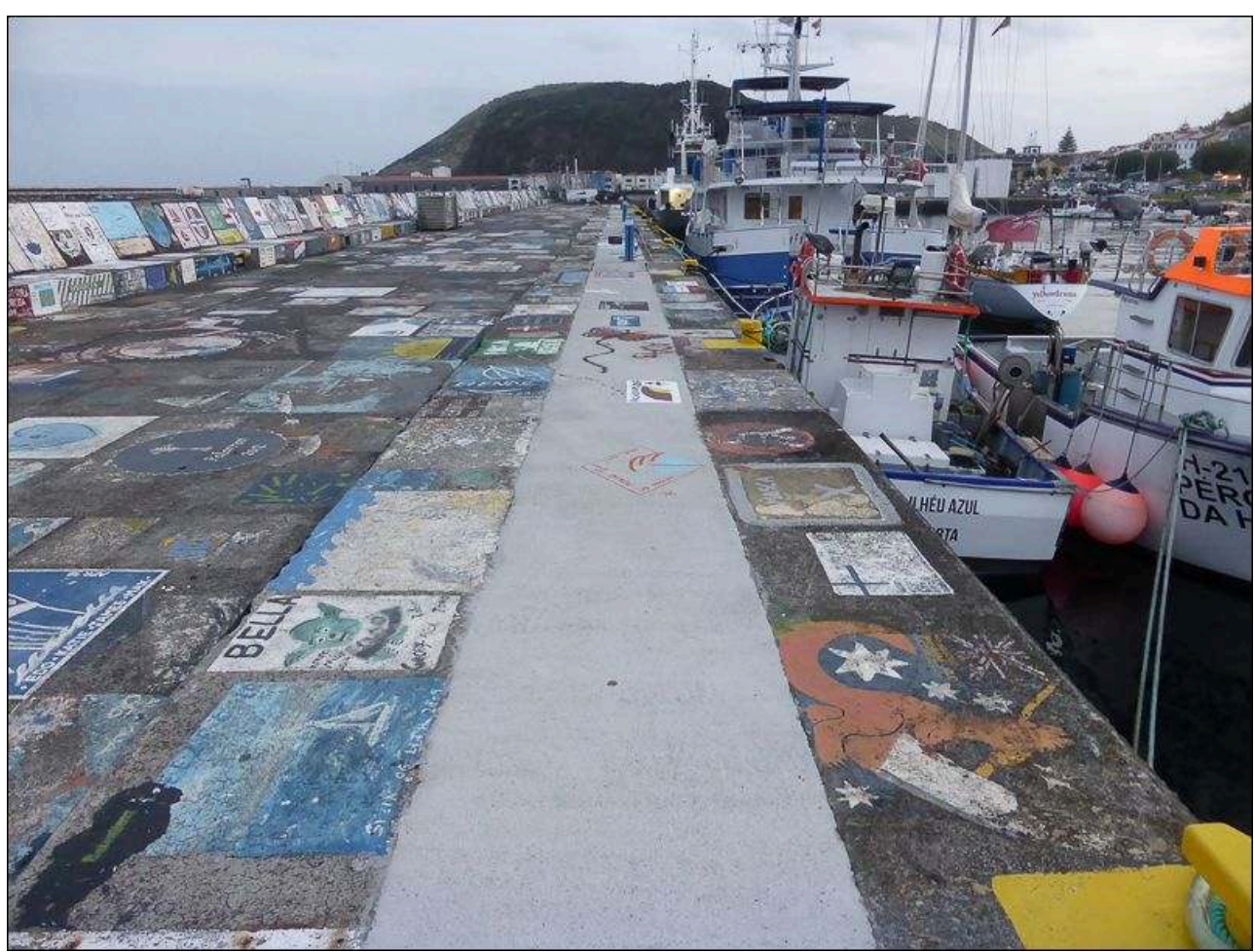

Auteur : L. Marrou, 2017

\section{Des œuvres au goût iodé et salé}

20 La quasi-totalité des peintures est réalisée par des marins de passage ${ }^{8}$. Ils sont donc extérieurs à la ville d'Horta dont ils ne connaissent parfois que la marina. Mais à leurs yeux, Horta est plus qu'une petite capitale insulaire. C'est l'endroit où ils touchent terre après plusieurs semaines de mer. C'est la terre et la ville par excellence après des jours sur l'immensité liquide. On peut ranger les œuvres des marins en trois grandes catégories, en suivant les types de langage utilisé :

- la majorité utilise le texte, conjonction de lettres et de chiffres (illustration 8). La peinture comporte alors le plus souvent un cadre, le nom de l'embarcation, une date de passage, le nom des équipiers. Plus rarement, les mots expriment une pensée, une philosophie, un message.

- d'autres privilégient la cartographie (illustration 9). C'est alors le trajet, déjà effectué ou à venir qui est mis en avant. Du fait de la position de l'archipel des Açores, les représentations représentent souvent le bassin Atlantique même si les images de circumnavigation ne sont pas absentes.

- un petit quart a une dimension artistique poussée (illustration 10). Les représentations peuvent être figuratives et l'emprunt au monde animal marin est alors souvent privilégié.

21 Les combinaisons entre les différents types sont fréquentes. Les représentations sont le plus souvent classiques mais depuis le début des années 2010, un petit pourcentage de peintures est réalisé à la bombe en reprenant les codes du graphe et de l'écriture urbaine. On retrouve ainsi à Horta toute la palette des expressions de la galaxie street art (Catz, 2013, p. 46 et suiv.) : graffiti, pochoir, tag et lettrage, installation, sculpture ou 
collage. On ne peut s'empêcher de penser, en observant ces parois colorées, au muralisme politique portugais (Schacter, 2014, p.9) qui a fleuri à Lisbonne et dans d'autres grandes villes portugaises après la Révolution des Æillets de 1974.

Illustration 8 - Peinture de l'équipage du Marta

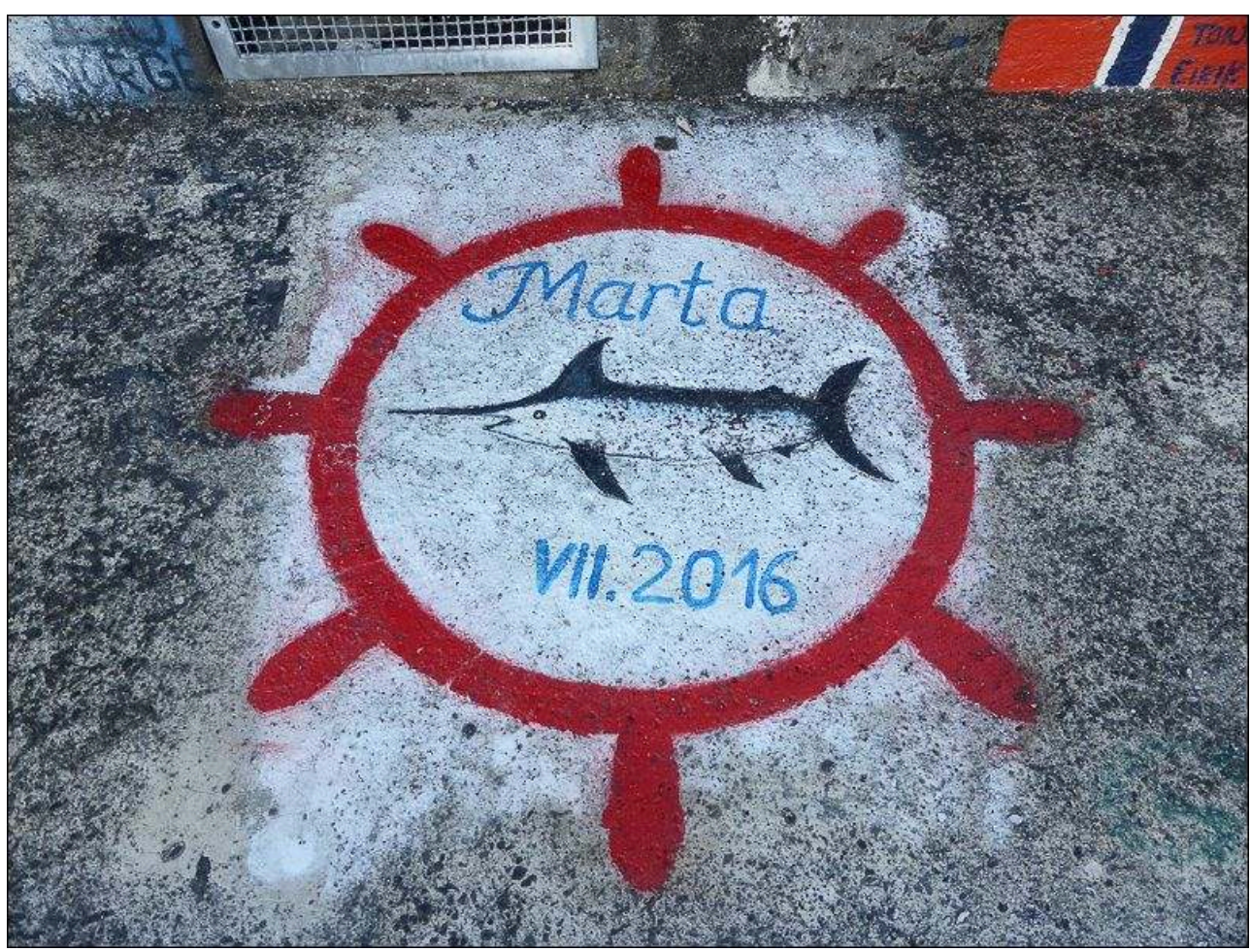

Auteur : L. Marrou, 2016 
Illustration 9 - Peinture de l'équipage du Ti-Soaz

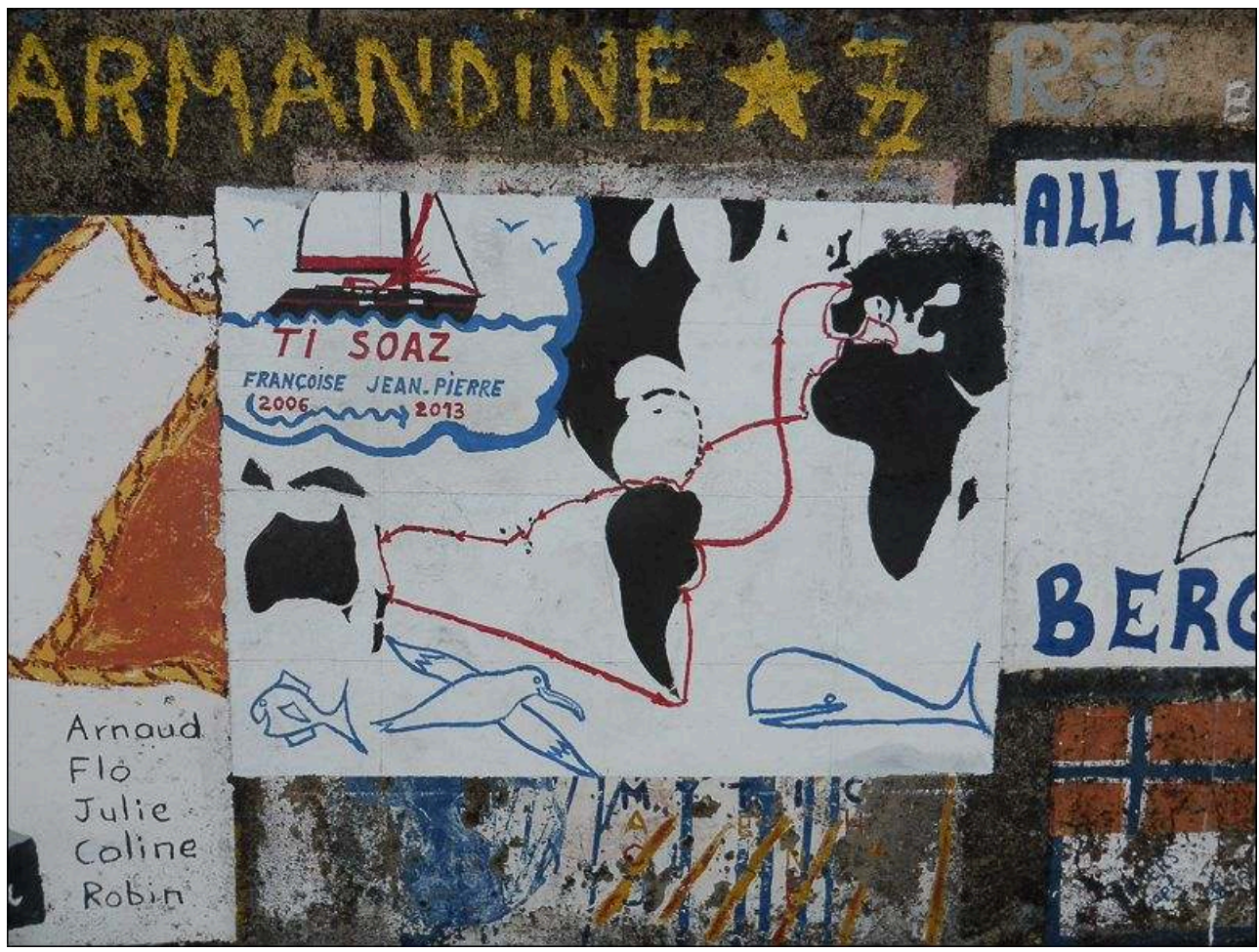

Auteur : L. Marrou, 2013

Illustration 10 - Peinture de l'équipage du Pi-Leve réalisée en 2008

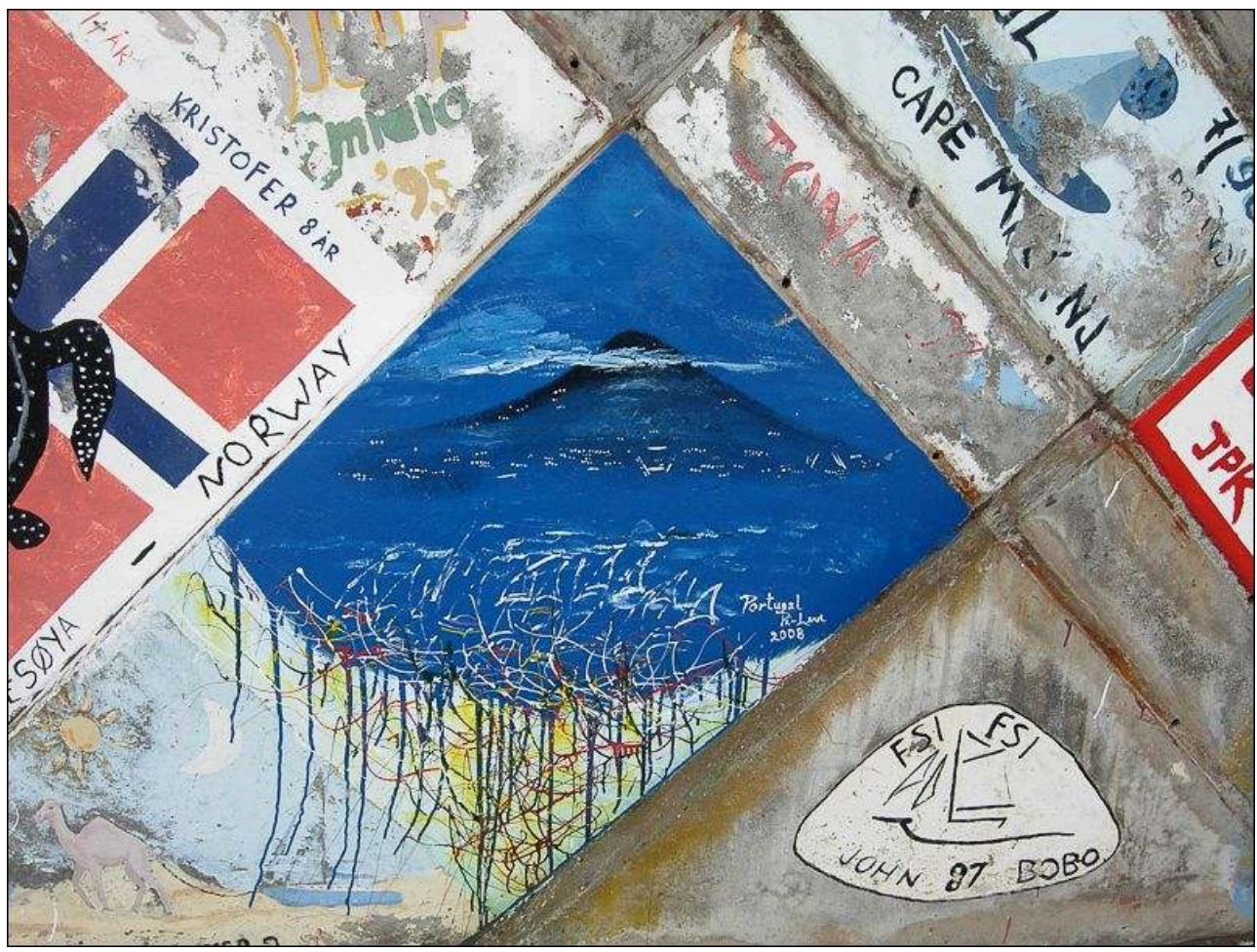

Auteur : L. Marrou, 2013. 
Depuis le milieu des années 2000, d'autres illustrateurs, étrangers à la sphère des marins, semblent intervenir sur la marina. Il n'y a pas de signature et il est extrêmement difficile de savoir qui fait quoi et combien sont les intervenants. Ils s'apparentent aux artistes de rue classiques. On a vu ainsi apparaître dans la marina des petits «champignons" rouges et blancs, type amanite tue-mouche ou reprenant le graphisme de certains dessins animés. Ces "champignons » ont la particularité d'être localisés en-dehors du champ habituel des peintures puisqu'ils privilégient les rochers à fleur d'eau dans les bassins en bordure de quai (illustrations 11 et 12). Cette volonté de se mettre à l'écart se retrouve aussi dans un grand dessin apparu hors de la marina, près du grand môle et utilisant les marches d'un escalier dans sa représentation. Cette réutilisation des éléments urbains fait partie des codes des dessinateurs de la marina. Il peut s'agir des boîtes de dérivation électrique, des bites d'amarrage ou des fondations d'un petit phare. D'une façon marginale, la marina a servi d'exutoire à des manifestations politiques locales en particulier lors d'un appel à la grève générale (illustration 13). Les slogans ont été peints, à la façon des représentations maritimes, sur un emplacement un peu délaissé par les navigateurs.

Illustration 11 - Peinture à l'écart des représentations de marins «Champignon/Maison de Schtroumpf "

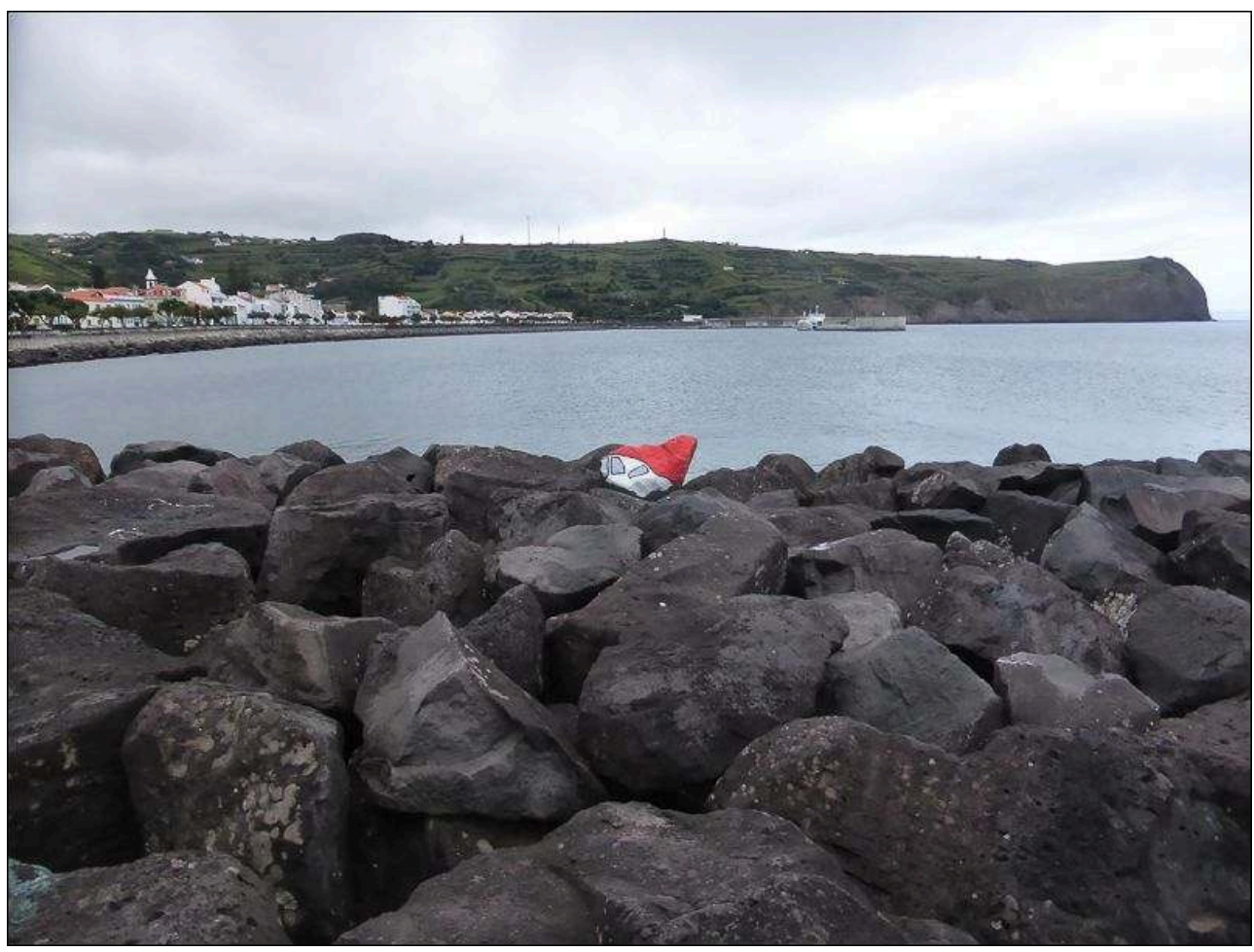

Auteur : L. Marrou, 2014 
Illustration 12 - Une bitte d'amarrage comme support pour les « Floating Sausage »

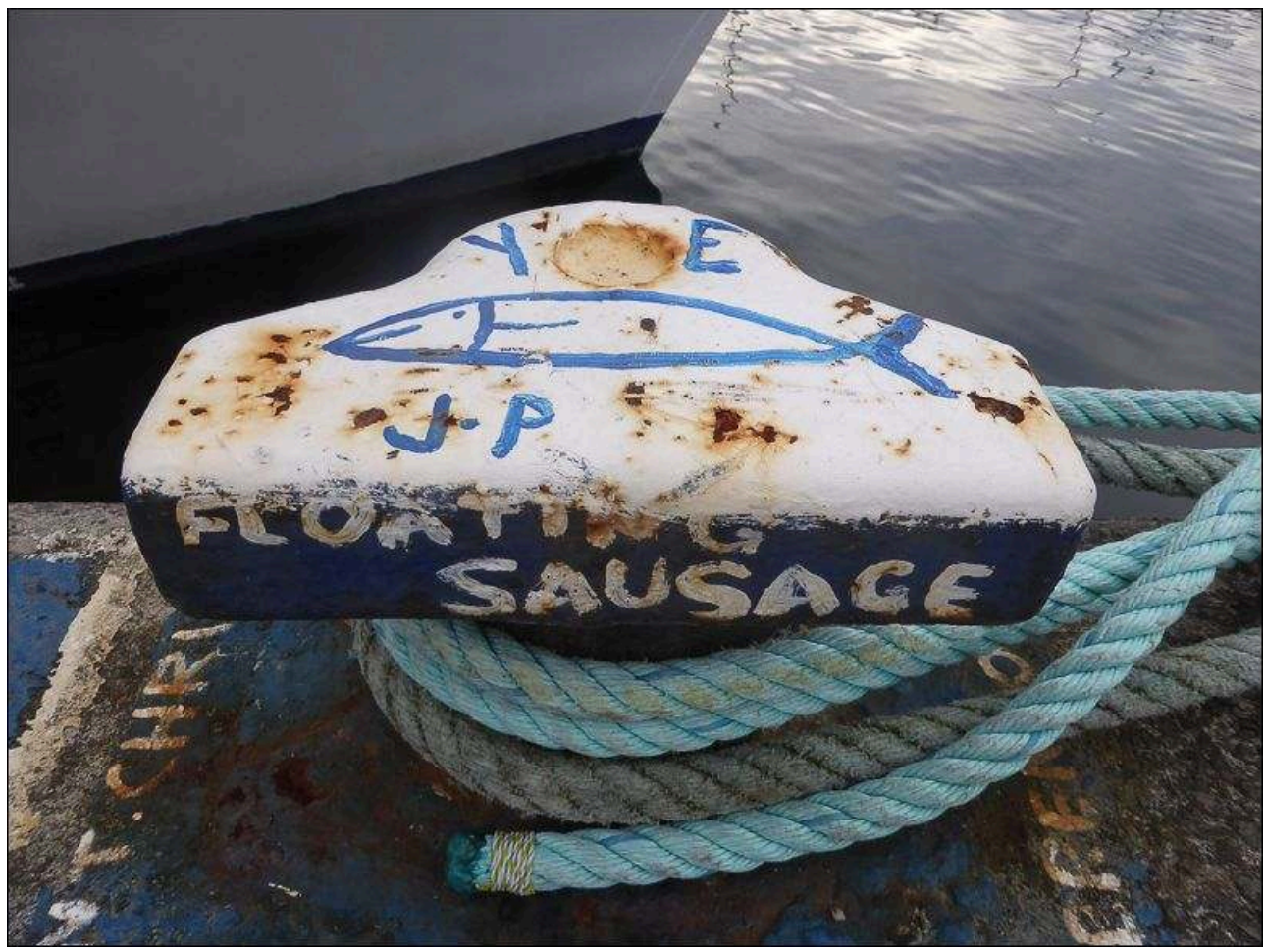

Auteur : L. Marrou, 2016

Illustration 13 - Peinture réalisée à l'occasion d'une journée des « Indignés » en 2011

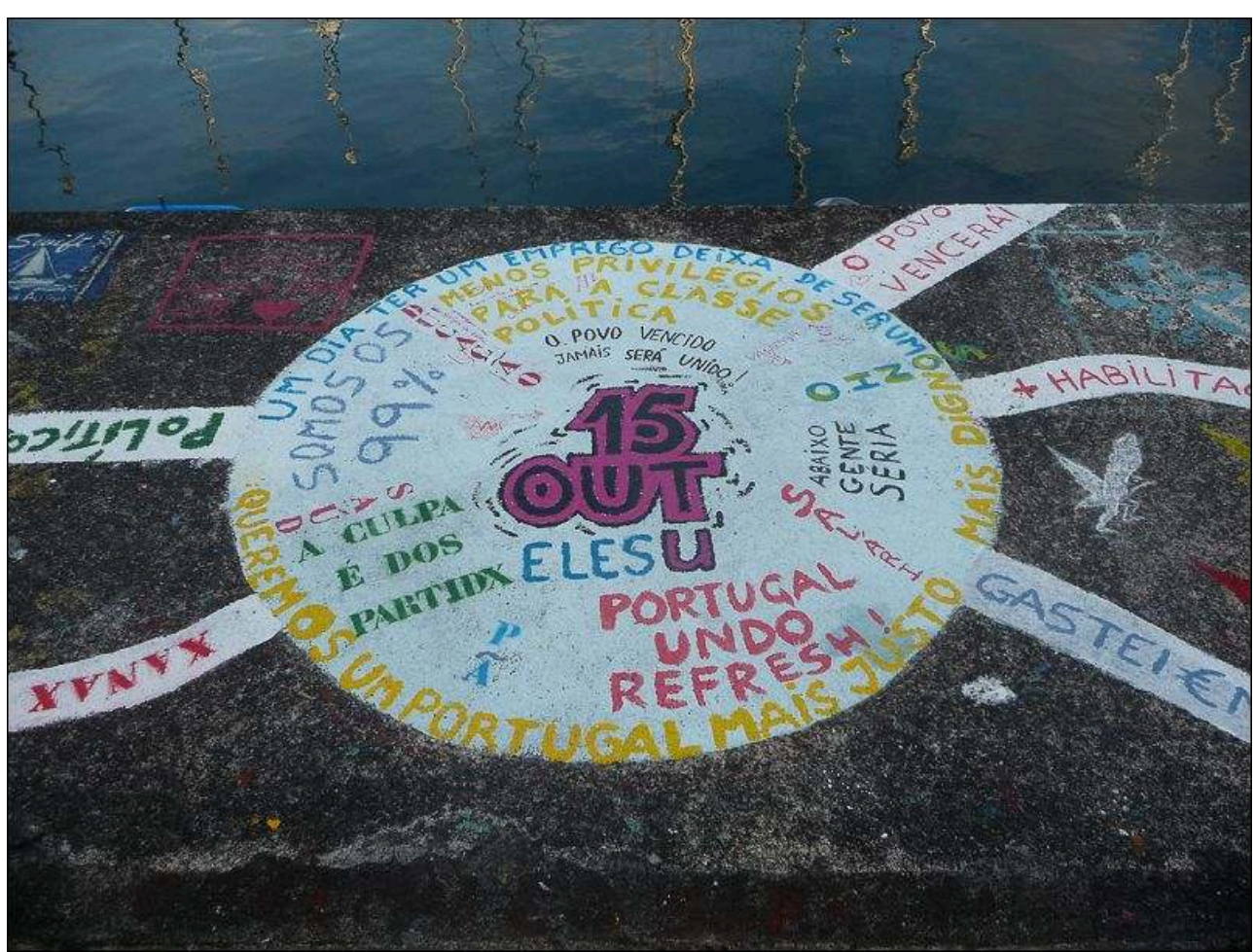

Pour plus de justice et de dignité et contre les partis.

Auteur : L. Marrou, 2011 


\section{Un éclat de fureur dans une ville-musée?} avec la ville d'Horta. Son intégration est complète et elle est au centre de toutes les réflexions urbaines de la municipalité. Elle est un élément incontournable de la réalité insulaire contemporaine. Le passage "d'excroissance " à centre est à mettre en partie au crédit de la spécificité artistique du port de plaisance. Ce dialogue repose avant tout sur des contrastes.

Le premier de ces contrastes repose sur une opposition entre la marina colorée et la ville en noir et blanc. Les couleurs de la marina sont avant tout celles des peintures des quais mais proviennent aussi des couleurs de certaines embarcations. Horta marie le noir et blanc dans tout son centre ancien. C'est d'abord le jeu des matériaux sur les façades des bâtiments entre les arêtes et les encorbellements en basalte noir et le reste des façades souvent traités à la chaux. C'est aussi le fait du traitement des trottoirs par la technique du pavé à la portugaise (calçada a portuguesa). Il s'agit d'une technique de décoration mariant des petits blocs de pierre blancs et noirs (illustration 14). Les décors peuvent être géométriques mais peuvent aussi représenter des éléments typiques du lieu. Aux abords de la marina, le traitement privilégie des moments de l'histoire ou des symboles architecturaux de l'île de Faial. La spontanéité colorée de la marina répond à la rigueur sobre de la ville ancienne.

Illustration 14 - Décor du trottoir de l'avenue dominant la marina d'Horta

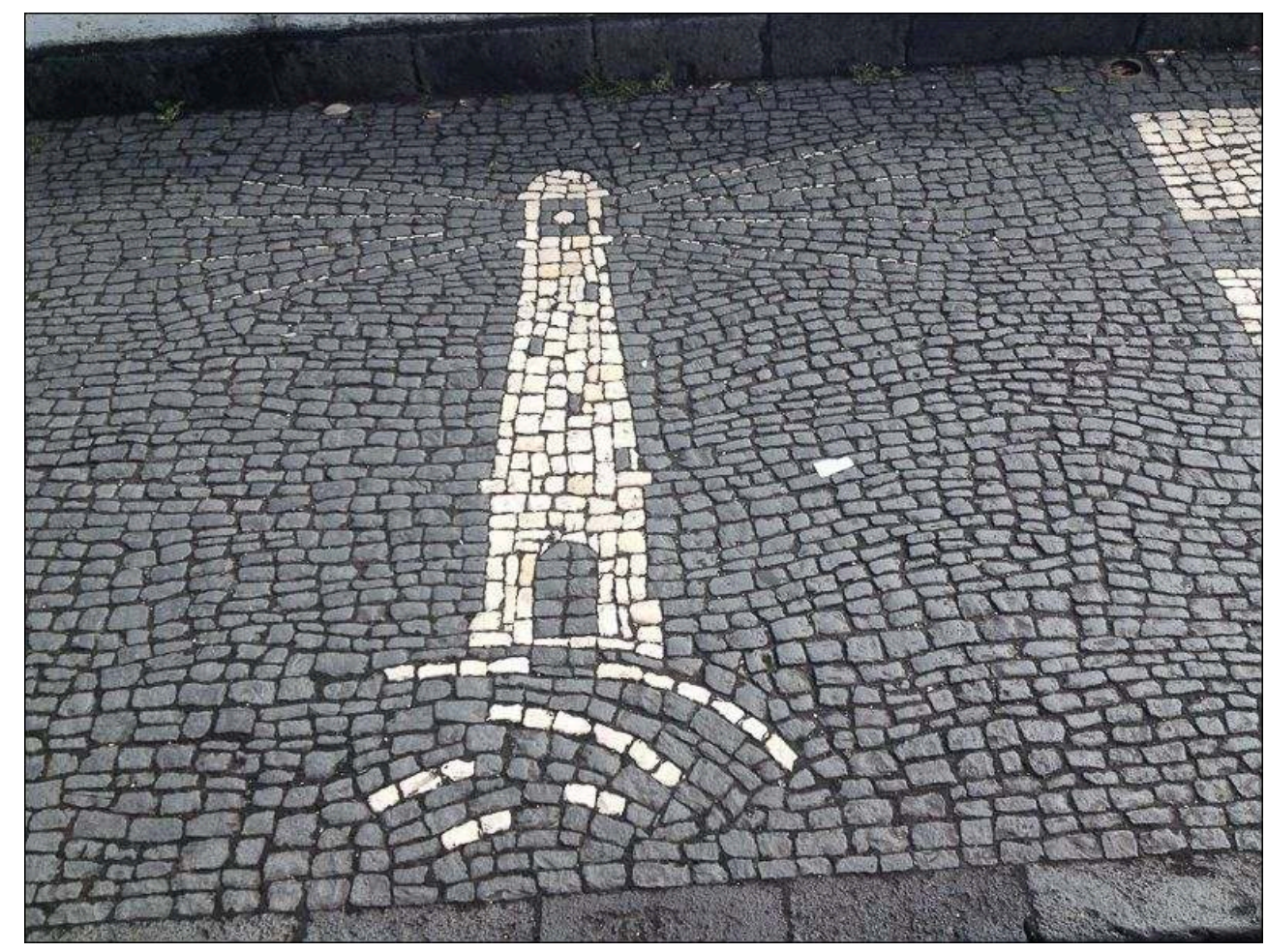

Auteur : L. Marrou, 2017

Tout au long de la fin du XXe siècle, la marina a représenté la modernité dans une ville où la tradition régnait. Cette modernité s'est incarnée dans le béton, le ciment et les lignes de la capitainerie. L'architecture contemporaine n'a pas eu beaucoup l'occasion 
de s'épanouir, et cette fin de siècle est marquée par l'inauguration de la marina en 1986 puis du bâtiment abritant l'Assemblée Législative Régionale en 1990. Le béton lisse et clair de la marina a été surprenant pour bien des habitants de la ville même si très vite des marins en shorts colorés et à la peau halée sont venus couvrir de signes et de courbes nouveaux ces cimaises portuaires. Les peintures de la marina ont représenté une véritable révolution culturelle. Les motifs, les techniques, les styles, les couleurs utilisés provenaient de cultures différentes, souvent urbaines (illustration 15). La marina était un kaléidoscope de couleurs que l'on observait du coin de l'œil. C'était nouveau et pour ainsi dire un peu étrange.

Illustration 15 - Peinture reprenant certains codes du dessin urbain et jouant des volumes du parapet de la marina

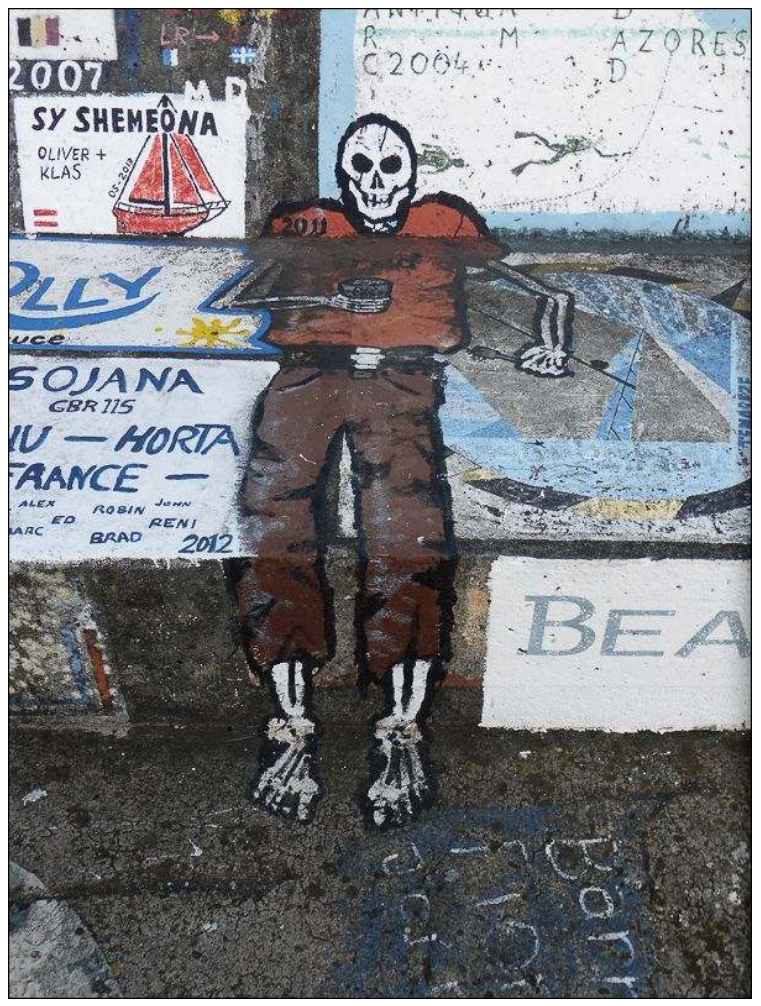

Auteur : L. Marrou, 2013

Un autre des contrastes tient à l'opposition entre une marina aux mains des " étrangers » et une ville tenue par les fayalais et les açoriens dans une cité qui cultive pourtant le cosmopolitisme depuis des lustres. Jusqu'au début des années 2000, les plaisanciers ont constitué une bonne partie des touristes présents dans l'île, si l'on fait abstraction du tourisme identitaire, de "saudade ", lié aux retours festifs de certains migrants. Les plaisanciers viennent d'Europe (Angleterre, France...) mais aussi du continent nord-américain. Ce sont des voyageurs, des aventuriers, des gens qui ont choisi une autre vie que celle du terrien ordinaire. Ce sont des marins, des gens de mer, des gens qui profitent de leurs loisirs. Ils sont de passage et ne font qu'un arrêt au port. Toujours, ils finissent par reprendre la mer, promettant de revenir, le plus tôt possible. Le mélange de ces deux mondes se fait aux interstices, dans certains bars, dans certains commerces (épiceries, accastilleurs...). 

une forme contemporaine s'opposant à une ville plus traditionnelle, moins moderne. Si chacun des 13700 gestes est l'œuvre d'un « étranger ", d'un « autre ", la marina prise dans son ensemble est bien partie intégrante de la ville avec sa faune, ses couleurs et son rythme un peu décalé. La ville d'Horta est coutumière de cette situation. C'est, au début du XXe siècle, la ville des câbles transatlantiques. Elle a vu arriver au tournant du siècle des centaines d'ingénieurs et techniciens qui s'occupent de la maintenance des câbles de télécommunication. Ils sont allemands, anglais, français, italiens, américains et font entrer une incroyable modernité dans une ville encore très rurale. Horta se peuple d'édifices art nouveau dont beaucoup sont encore debout.

Illustration 16 - Peintures murales dans le centre-ville d'Horta

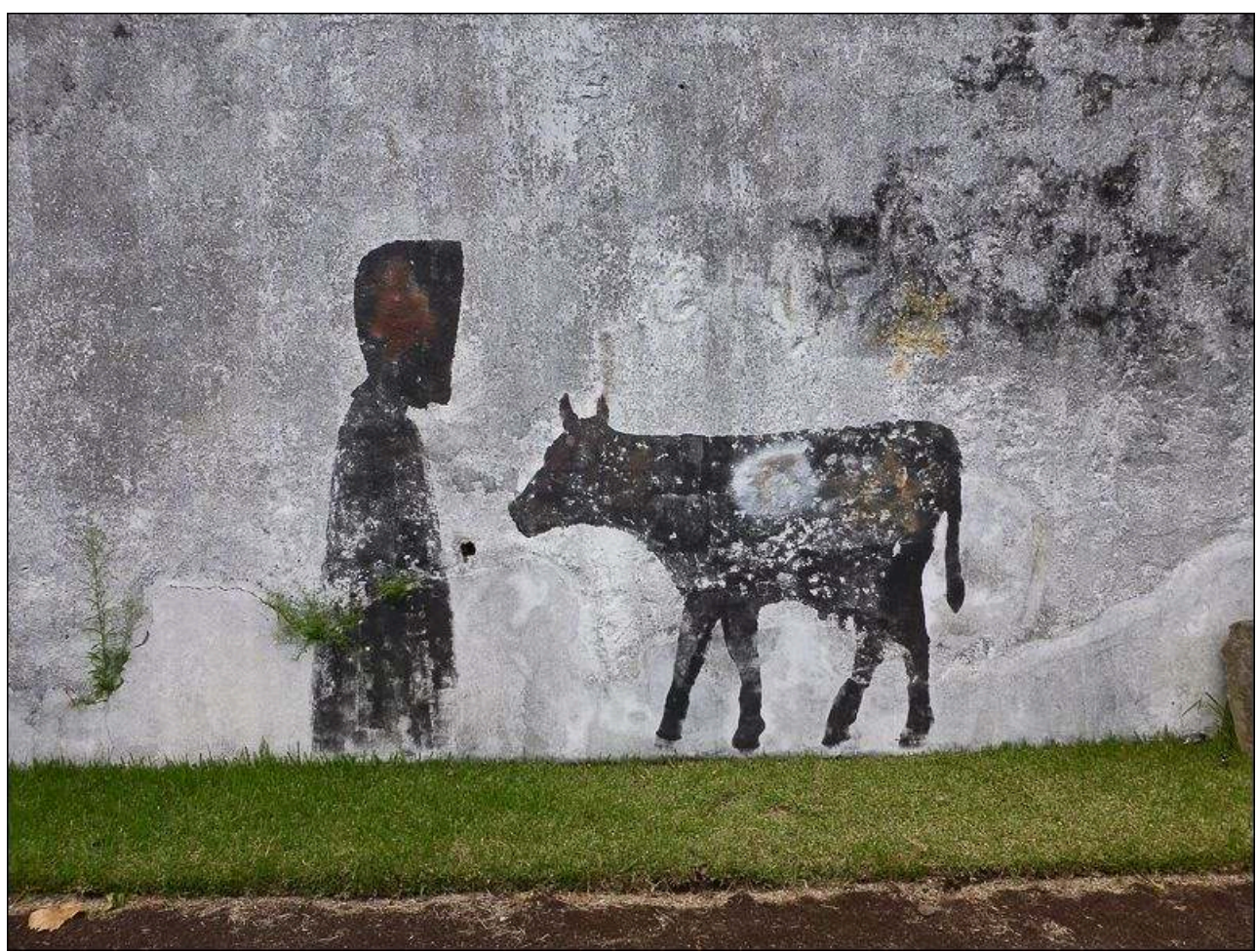

Peintures représentant une femme en habit traditionnel et une vache

Auteur : L. Marrou, 2017

Il est étonnant de voir comment la ville contemporaine, y compris dans son extension moderne qui est partie à l'assaut des collines surplombant la baie, reste d'une grande sagesse architecturale et iconographique (Fernandes, 1996). Les graphes et les tags sont peu nombreux. Un seul artiste « urbain » semble opérer en ville (illustration 16). Ces personnages sont en noir. Ils représentent le plus souvent soit une vache, soit une silhouette de femme portant l'habit traditionnel, la capote qui couvrait la tête des fayalaises.

\section{Ne pas user l'amarre jusqu'à la corde}

L'âge d'or de la marina d'Horta est sans doute aujourd'hui derrière elle et il faut donc s'assurer de son bon amarrage à la ville. Depuis le début des années 2010, le port de 
plaisance d'Horta est entré dans une nouvelle ère. Les grands équilibres changent. Le réaménagement de la façade maritime d'Horta sous les hospices de la mairie est en cours depuis 2017 et les nouvelles pratiques maritimes et touristiques rebattent les cartes. Le temps de la maturité est arrivé et le marin de passage délaisse parfois les pinceaux au profit du wifi et des caméras embarquées. La valorisation du territoire s'en trouve modifiée.

Illustration 17 - Carte de la situation de la ville d'Horta sur l'île de Faial

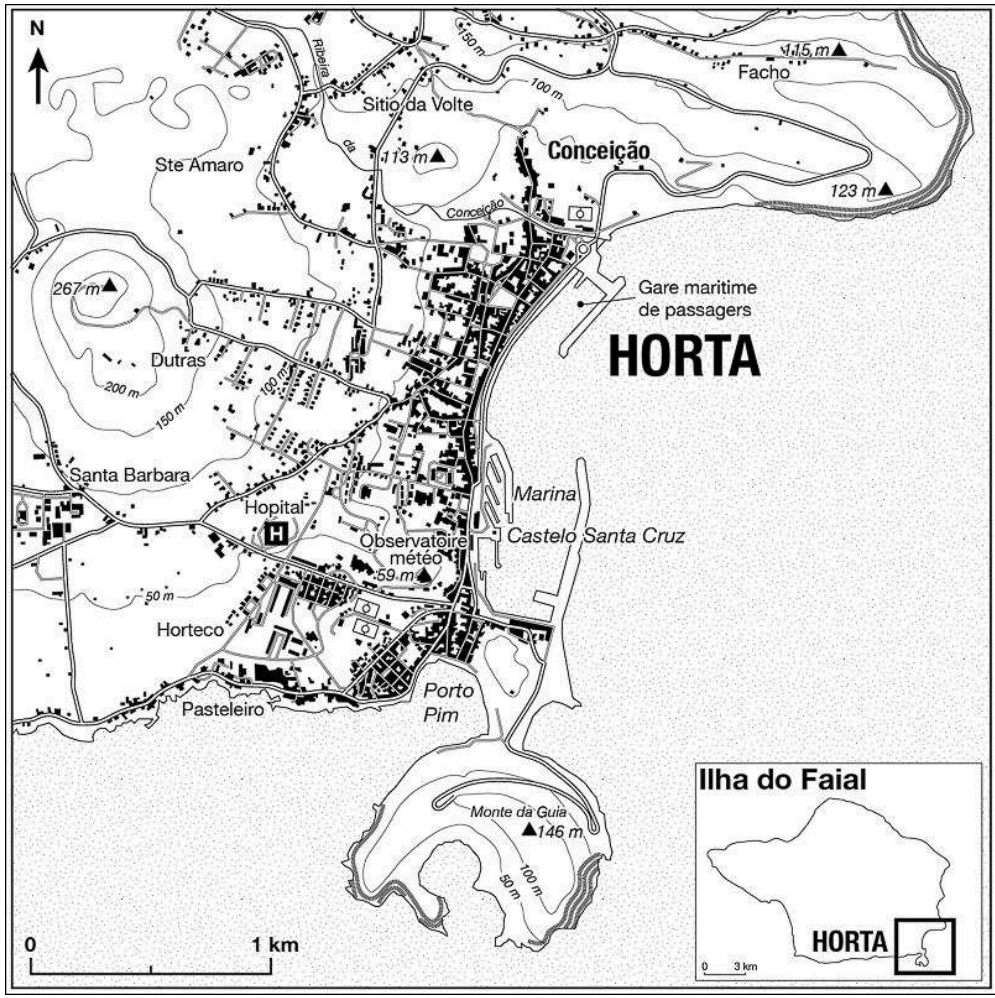

Auteur: P. Brunello

\section{L'art urbain à l'heure des réseaux}

Si le dialogue entre la marina et la ville est contemporain, il s'inscrit dans un dialogue historique entre les deux extrémités de la baie qui forme le cadre du développement urbain d'Horta (illustration 17). L'histoire de la ville est un éternel dialogue entre le noyau proche de la Ribeira dos Flamengos au Nord et celui d'Angustias et de la plage de Porto Pim au Sud. Le premier concentre la partie ancienne et noble de la cité, alors que le second est traditionnellement celui des pêcheurs. La ville s'est développée en comblant rapidement l'espace entre les deux, avant de s'attaquer aux pentes et de s'étendre sur les versants dominant la baie. Depuis sa création, la marina a pesé d'un poids remarquable dans la dynamique urbaine des trente dernières années.

Au tournant $\mathrm{du} \mathrm{XX}^{\mathrm{e}}$ siècle, la marina est le symbole de la modernité de la petite ville açorienne. Les peintures murales du port deviennent l'un des ex-libris de la cité. Elles sont présentes dans les devantures des commerces et sur les tourniquets de cartes postales. À l'occasion du réaménagement de l'aéroport de Faial à quelques kilomètres de la ville, la totalité de la décoration de la cafétéria est composée de répliques de 
peintures de la marina (illustration 18). C'est l'époque où les guides touristiques commencent à s'intéresser à l'archipel des Açores. A Faial, à l'instar du volcan du Capelinho, la marina et ses œuvres commencent à avoir une certaine notoriété.

Illustration 18 - Décoration de la cafétéria de l'aéroport de l'île de Faial à Castelo Branco

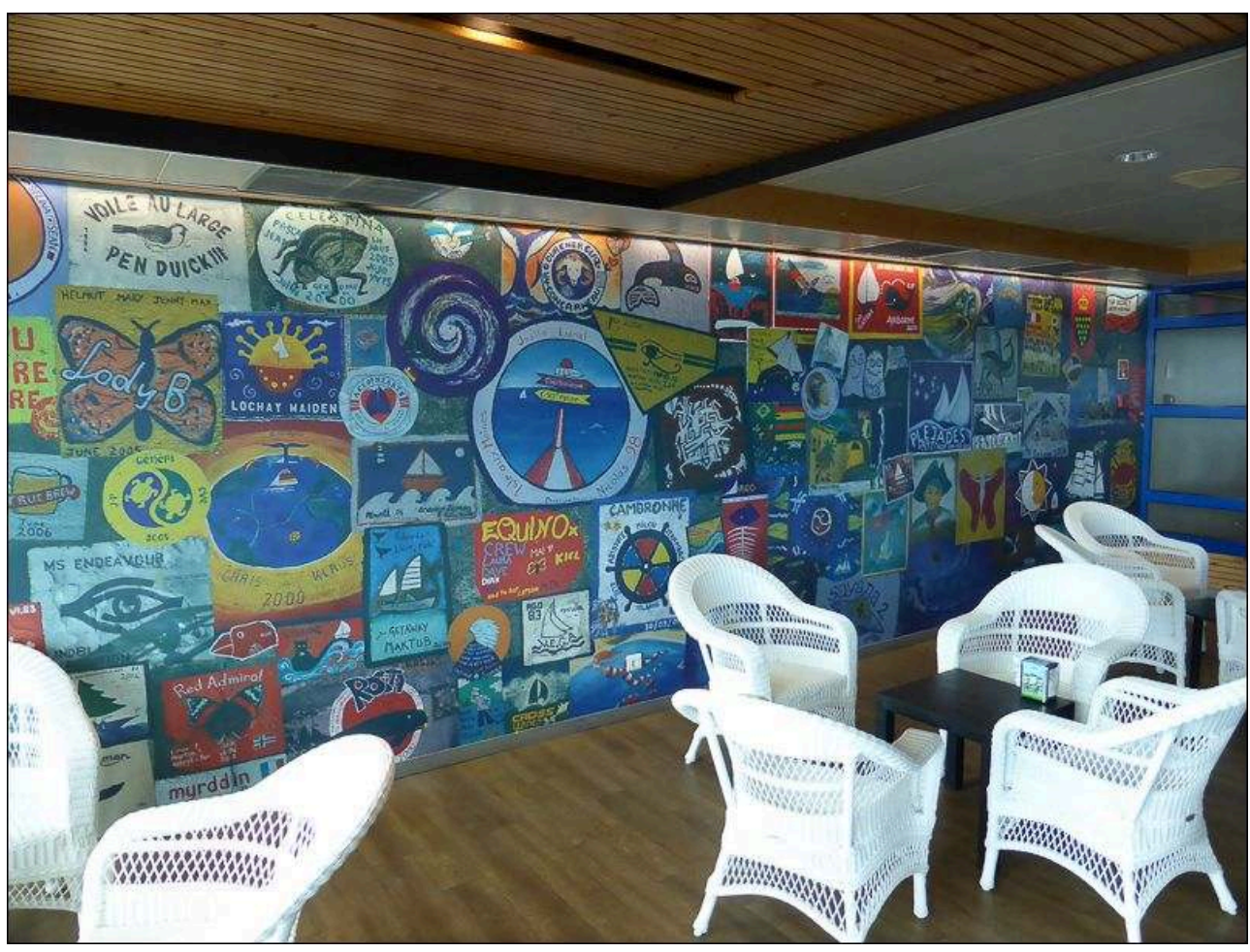

Décoration reprenant des peintures de la marina d'Horta.

Auteur : L. Marrou, 2013.

Au développement touristique s'est ajoutée, dans cette partie de Horta, la construction du premier hypermarché de la ville et du nouvel hôpital général de l'île. À partir de 2010, l'idée d'une réflexion pour un aménagement global de la façade maritime de la ville s'est imposée. L'acte fondateur en a été le déménagement du terminal de passagers maritime (environ 200000 personnes à l'année) avec la création du nouveau port de passagers (liaison inter-îles et bateau de croisière). Lui qui jouxtait la marina est désormais installé à l'autre bout de la baie, au débouché de la Ribeira dos Flamengos. Le béton y reste gris, terne. Il n'y a eu ni diffusion par mimétisme, ni volonté politique d'institutionnaliser ou de favoriser une pratique qui a, dans l'ensemble, la faveur des usagers.

33 La municipalité d'Horta a décidé d'investir 50 millions d'euros pour le réaménagement de la façade maritime de la ville pour les années 2018-2023. Le slogan de l'opération est «Tourner de nouveau la ville vers la mer ». La marina n'est touchée qu'à la marge, elle qui dépend pour son aménagement, avant tout, de l'administration portuaire. Elle va cependant bénéficier de la remise en ordre et de l'intégration des activités d'observation de cétacés et de pêche sportive dans des infrastructures autres que provisoires. L'impression qui est donnée est celle de la « remise à niveau » de la ville par rapport à une marina qui a longtemps été comme en "avance» sur son territoire d'installation. Cette situation incite la marina à reprendre une longueur d'avance et les peintures pourraient y prendre une place prépondérante. 
L'archipel des Açores et l'île de Faial doivent faire face à un changement profond dans les formes de l'activité touristique. Pour Horta on peut en isoler deux. D'une part, la desserte de l'archipel par des compagnies aériennes à bas coût est en train de modifier considérablement le profil des touristes et leurs attentes. D'autre part, la plaisance prend chaque jour de nouvelles formes et l'adaptation est nécessaire en permanence même si la localisation exceptionnelle de Faial dans le bassin maritime atlantique lui assure une forme de pérennité.

\section{Faire avec les nouveaux touristes}

35 A Horta le changement le plus palpable est la modification du profil des marins qui abordent la marina (Marrou, 2017). Globalement le nombre d'embarcations faisant escale chaque année dans la marina est constant depuis le début des années 2000, entre 1200 et 1400 . Cette situation s'explique par la multiplication des infrastructures portuaires dans l'archipel et dans l'ensemble de la Macaronésie. Mais les équipages sont en train de rajeunir. Au plaisancier traditionnel, un peu loup de mer, "aventurier ", « voileux » est en train de succéder progressivement des équipages plus jeunes, adeptes des technologies d'aide à la navigation et des "fenêtres météo ». Ils sont souvent dans une optique de "loisirs", sont moins propriétaires de leur embarcation et n'effectuent parfois que des demi-transats quitte à arriver en bateau à Horta et à en repartir en avion! Ils drainent avec eux famille ou amis qui n'hésitent pas à venir les rencontrer en profitant de vacances ponctuelles.

Dans ce contexte, les peintures murales de la marina d'Horta prennent une autre dimension et peut être aussi une nouvelle signification (Marrou, 2018). Même si le dénombrement annuel des peintures est extrêmement difficile à tenir, il est désormais patent que l'on assiste insensiblement à une baisse du nombre de réalisations annuelles de l'ordre de 500 à 550. Cela signifie que plus d'un équipage sur deux ne laisse pas de témoignage pictural de son passage. Or face à cette situation, l'engouement pour les peintures n'a jamais été aussi important. D'avril à octobre, ce sont chaque jour des centaines de personne qui fréquentent la marina et qui profitent de cet étonnant lieu d'exposition. Parmi les «fréquenteurs » de la marina, les plaisanciers sont désormais une minorité (illustration 19). Le joggeur urbain, le promeneur contempteur et le touriste lambda sont majoritaires et omniprésents. 


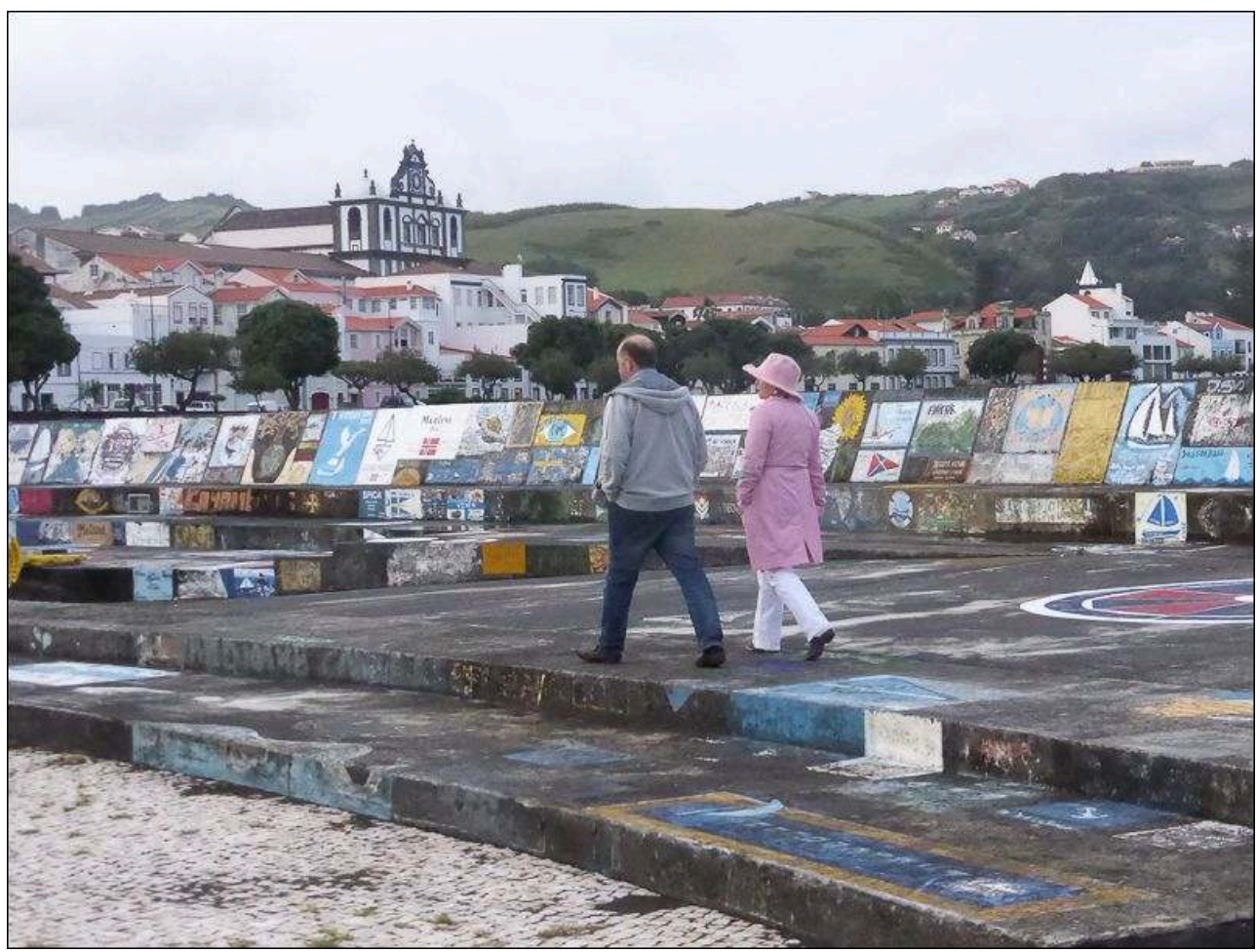

Auteur : L. Marrou, 2017

Les peintures de la marina sont appelées à sortir toujours plus du cercle d'amateurs marins initiaux. Elles transitent sur les réseaux sociaux. Parfois le web semble avoir remplacé la rue ou le quai (Fedel, 2013, p. 6). Le public s'élargit. Les peintures s'ouvrent sur la ville ce qui devrait inciter à mieux les mettre en valeur, mieux les expliciter, mieux les intégrer. Les nouvelles populations de touristes sont souvent jeunes, urbaines, connectées et semblent fort ouvertes aux nouvelles formes d'expression graphique dans l'espace urbain. Elles s'émerveillent de voir en un seul lieu ce qu'elles ont l'habitude de trouver sur des sites artistiques en ligne mais en provenance de centaines de lieux géographiques différents. Là tout est sous la main, en quelques kilomètres de quais.

\section{Mirer les murs !}

L'originalité de Horta est forte au sein de l'archipel dans le domaine du street art. La ville de Ponta Delgada sur l'île de Sao Miguel, la ville la plus importante de la région autonome des Açores, est la seule à offrir un véritable vivier d'artistes qui utilise l'espace urbain comme lieu d'expression. Il suffit pour s'en convaincre d'arpenter les rues proches de l'université des Açores (illustration 20). Ponta Delgada a longtemps aussi été la seule ville à offrir un véritable parcours de peintures urbaines, essentiellement fruits de commandes publiques qui ornent différents quartiers de la ville (illustration 21). La plus grande ville des Açores est la seule à apparaître sur la carte du monde 9 qui recense des œuvres du street art. 
Illustration 20 - Peinture à Ponta Delgada (île de Sao Miguel) en face de l'entrée de l'Université des Açores

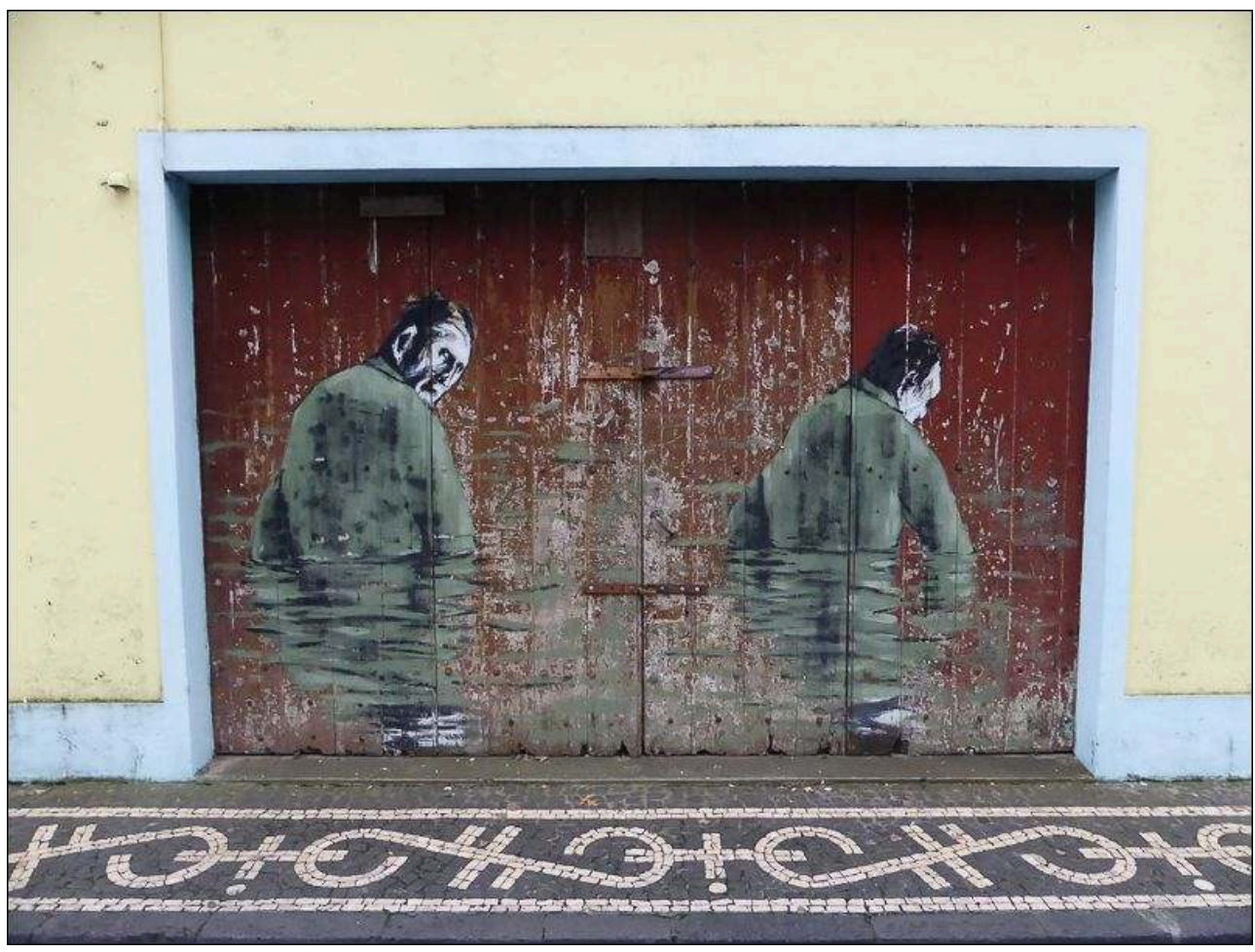

Auteur: L. Marrou, 2017

Illustration 21 - Peinture murale « Reskate », 2016

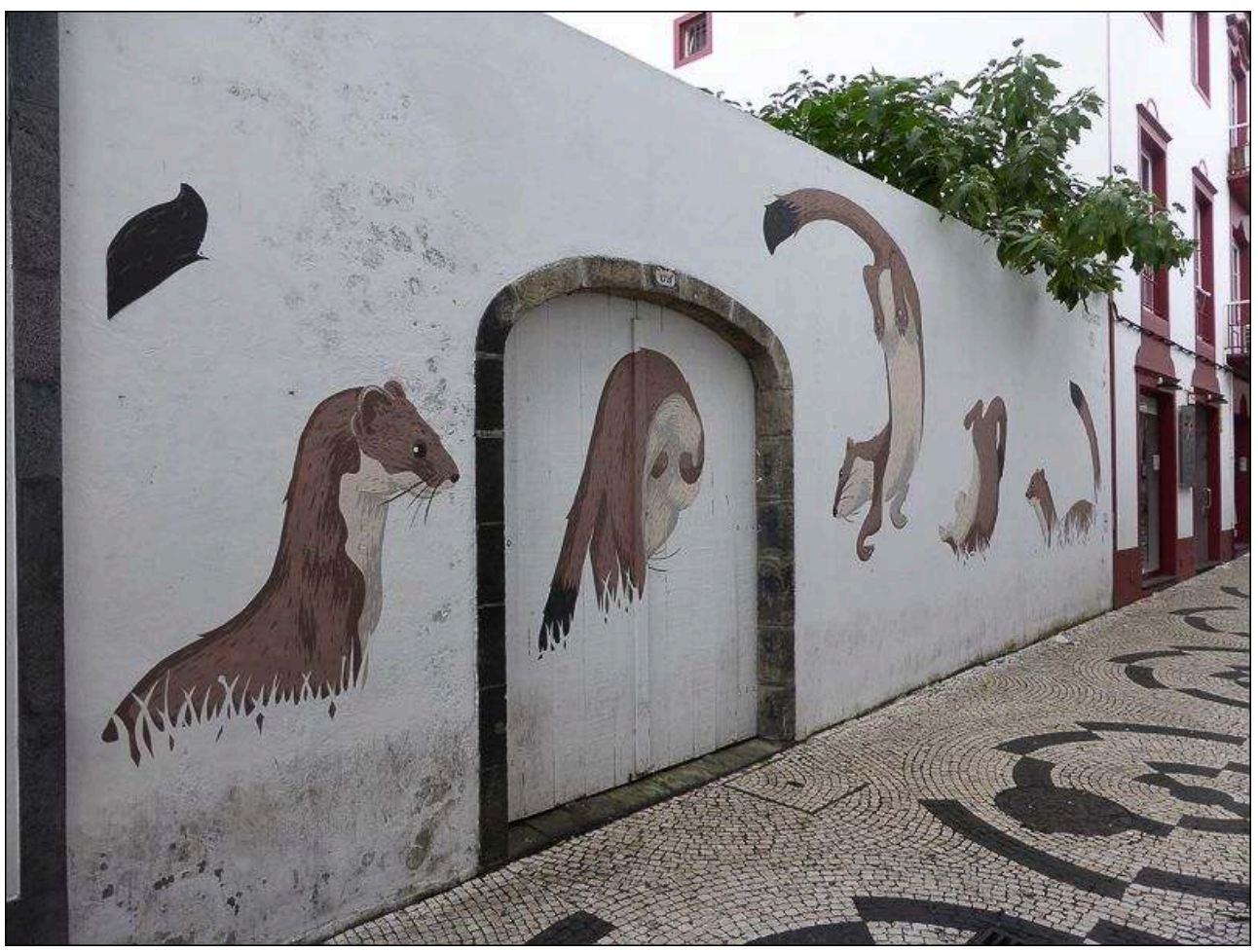

Peinture incluse dans le circuit d'Art Public du centre-ville de Ponta Delgada dans l'île de Sao Miguel. Auteur : L. Marrou, 2017. 
À Flores, dans l'île la plus occidentale de l'archipel, la petite ville de Santa Cruz propose depuis 2017 un ensemble remarquable de peintures murales de grandes tailles sur les murs de la ville. Elles sont l'œuvre d'une seule et même artiste, Morgan Bricca ${ }^{10}$, et représentent des éléments de la faune et de la flore locales, essentiellement des oiseaux et des fleurs (illustration 22). L'île est entièrement dans le périmètre d'une réserve de biosphère et les peintures ont été déployées grâce à l'appui d'une association environnementale locale mêlant florentins et étrangers. Elles connaissent déjà une notoriété certaine par l'entremise des réseaux sociaux.

Illustration 22 - Peinture de Morgan Bricco (Tentilhao-Pinson)

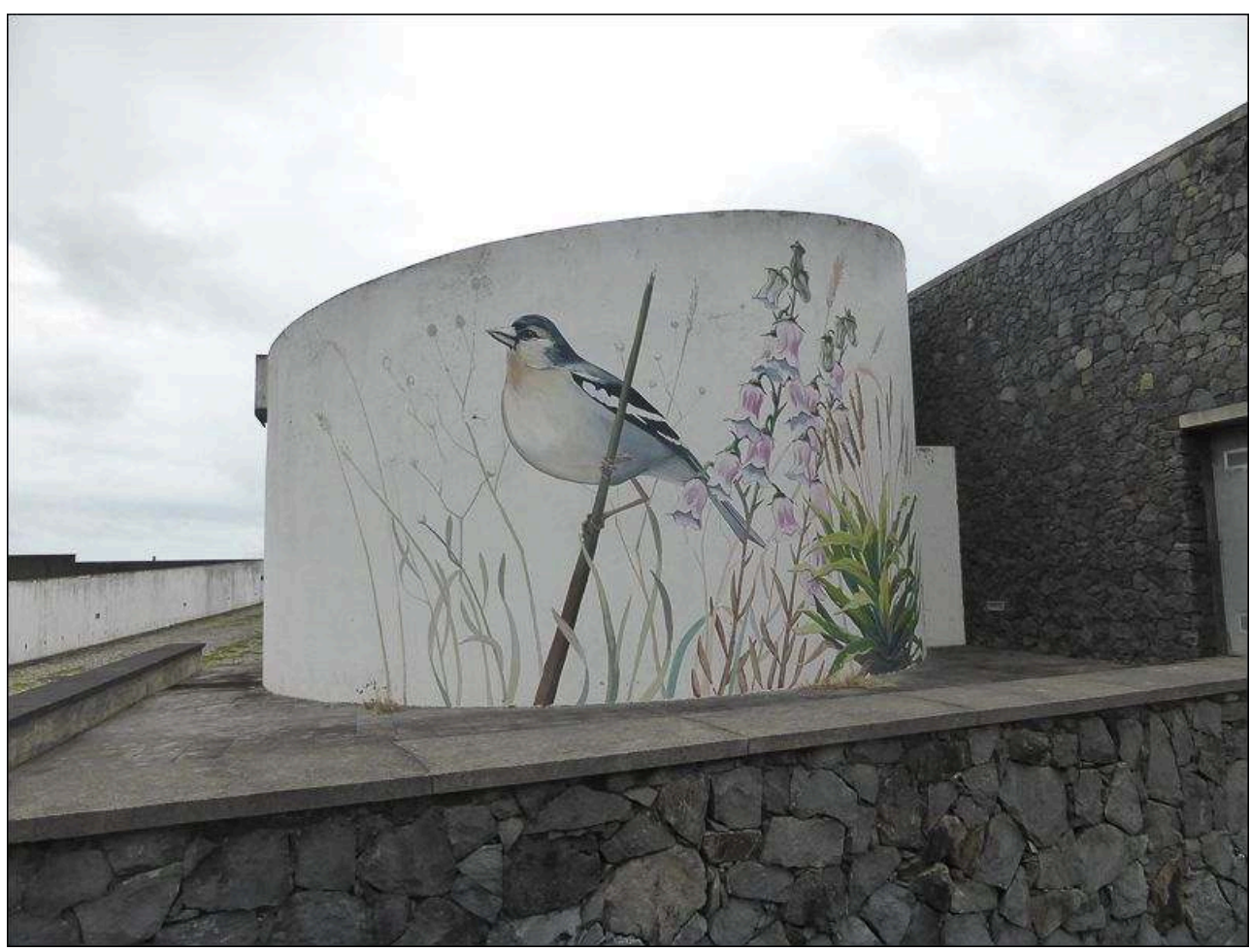

À l'arrière du Tribunal de Santa Cruz das Flores dans le cadre du projet Nature is home soutenu par I'Association Choki-Açores.

Auteur : L. Marrou, 2017)

Le mouvement initié dans la marina d'Horta s'est exporté dans d'autres marinas des Açores, mais aussi par exemple à Madère où la marina de Funchal présente plusieurs centaines d'œuvres. La création de nouvelles infrastructures pour le développement de la plaisance aux Açores a offert de belles opportunités. La mode ne prend pas dans la marina de Ponta Delgada malgré quelques essais. Elle est plus "institutionnalisée » dans celle de Praia da Vitoria sur l'île de Terceira où l'aménageur de la marina a fait appel à des décorateurs, notamment par la création de panneaux d'azulejos, les carreaux de céramique portugais. Il n'y a que dans la minuscule marina de Lajes das Flores que la spontanéité est de mise. L'île est la première sur la route des voiliers en provenance des Amériques et les talents artistiques des plaisanciers en escale s'épanchent alors sans limites.

Le défi à relever pour la capitainerie et la mairie d'Horta est de réussir à capitaliser sur les peintures de la marina et de parvenir à faire le lien avec le tout petit noyau d'artistes locaux souvent proches des étudiants travaillant en biologie marine et 
océanographie. Il faut tout à la fois mieux connaître pour ensuite être capable de partager. À notre connaissance, il n'existe pas de personne dédiée aux peintures murales à la capitainerie du port d'Horta même si celle-ci incite au maintien de la tradition en mettant à disposition des équipages non pourvus un «kit» peinture contenant quelques pots de couleurs et des pinceaux.

Illustration 23 - Peinture de l'équipage du Profile, une des peintures les plus célèbres de la marina

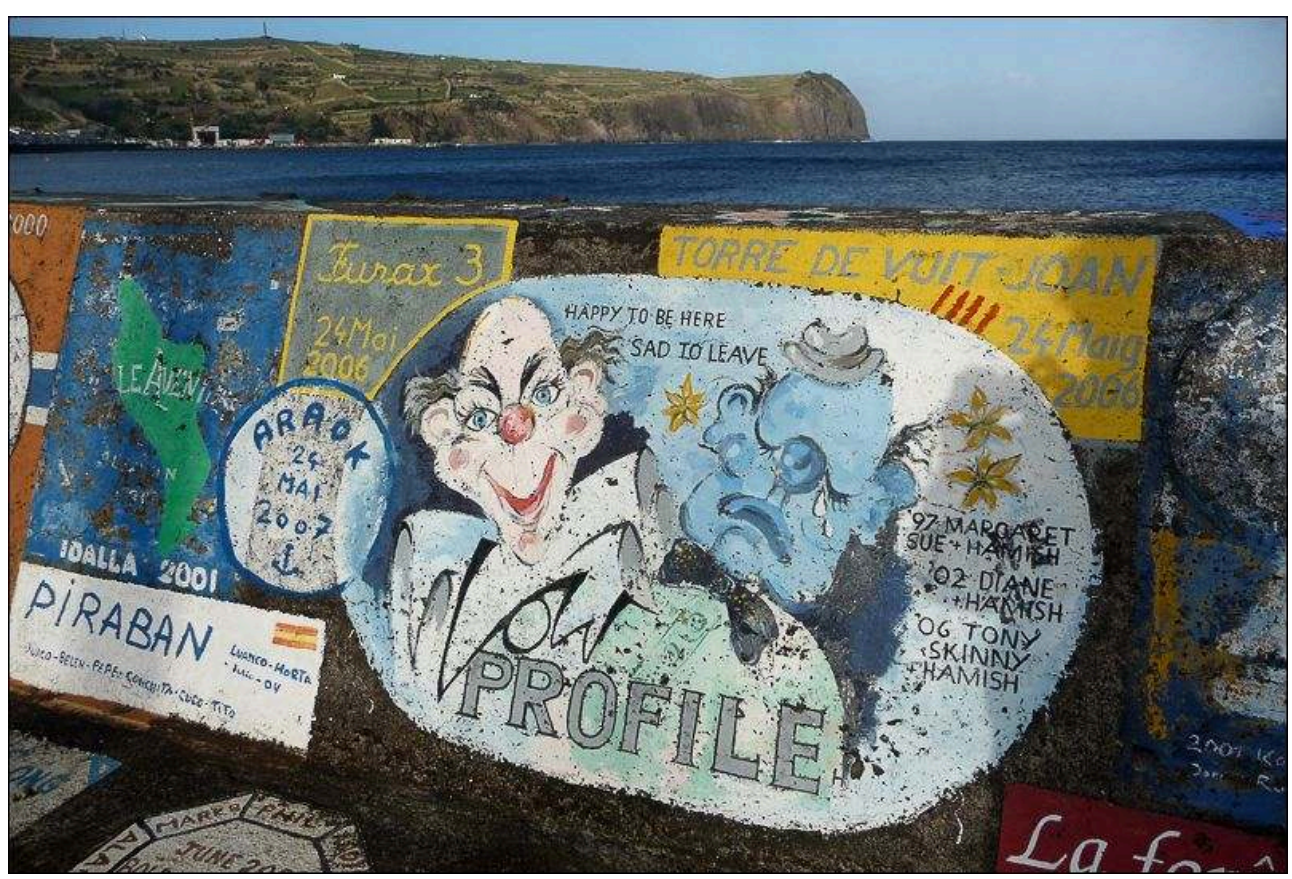

Auteur : L. Marrou, 2010

L'encadrement de la pratique n'est pas à l'horizon. Elle est depuis toujours libre, éphémère, irrégulière. Sa mise en valeur s'avère pourtant incontournable et cela d'autant qu'il ne reste probablement plus de peintures de la première couche initiale, celle qui a recouvert le béton neuf au milieu des années 1980. Certaines des peintures ont connu une notoriété plus forte que d'autres en raison de la qualité artistique, de la teneur du message ou de leurs reprises sur certains messages publicitaires ou éditoriaux (illustration 23). On pense au clown de l'équipage du Profile qui proclame: "Happy to be here. Sad to leave» et qui a été utilisé sur de nombreux supports promotionnels de la ville. La question de la qualité des œuvres éphémères revient souvent dans les débats. La très grande majorité des œuvres de la marina d'Horta n'ont pas de valeur artistique affirmée. Elles ne sont pas là pour ça. C'est l'ensemble qui forme une œuvre unique au monde. Le recensement des peintures parait un préalable à toutes les mises en valeur possibles. De même, il nous semble que désormais un accompagnement de la visite devienne nécessaire du fait de la moindre spécialisation «nautique » des gens qui profitent de cette immense «toile à ciel ouvert » (Bottani, 2016). Il n'est pas question de droit d'entrée évidemment mais plus d'un petit rappel historique et pratique par le biais de bornes interactives, d'applications, de panneaux ou d'un dépliant. Des "visites ", comme cela existe à Marseille ou à Montréal sont à envisager (Bottani, 2016, p. 96). 


\section{Conclusion}

La valorisation des peintures est à l'ordre du jour. Elle doit être à la hauteur de la reconnaissance d'un patrimoine « unique ou du moins exceptionnel ». La décoration de la marina d'Horta peut être considérée comme un chef d'œuvre collectif du génie créateur humain. C'est la superposition des œuvres qui fait la valeur de l'ensemble. Elle rapporte surtout un témoignage étonnant d'une tradition culturelle qui est propre aux gens de mer et aux marins. Celle-ci s'inscrit dans la lignée des ex-votos ou des graffitis et sculptures que l'on trouve fréquemment dans les ports. Elle dit à sa façon la mer, le voyage et la communion avec l'océan. À l'instar de la réappropriation de la ville par les tenants du street art (Dogheria, 2016, p. 202), les peintures de la marina peuvent être vues comme une réappropriation de la terre par le marin. Les équipiers du bateau forment au même titre que l'équipe qui entoure l'artiste reconnu de street art, un équipage, une bande, que rend bien le terme anglais de « crew» (Landes, 2015, p. 4). Ils ne se contentent pas d'embellir les murs par leurs dessins, ils s'en prennent aussi à la chaussée comme pour mieux s'ancrer à terre, au sol.

Illustrations 24 - Peinture façon « lettrage » sur le même parapet : « One Crew », datant de 2014

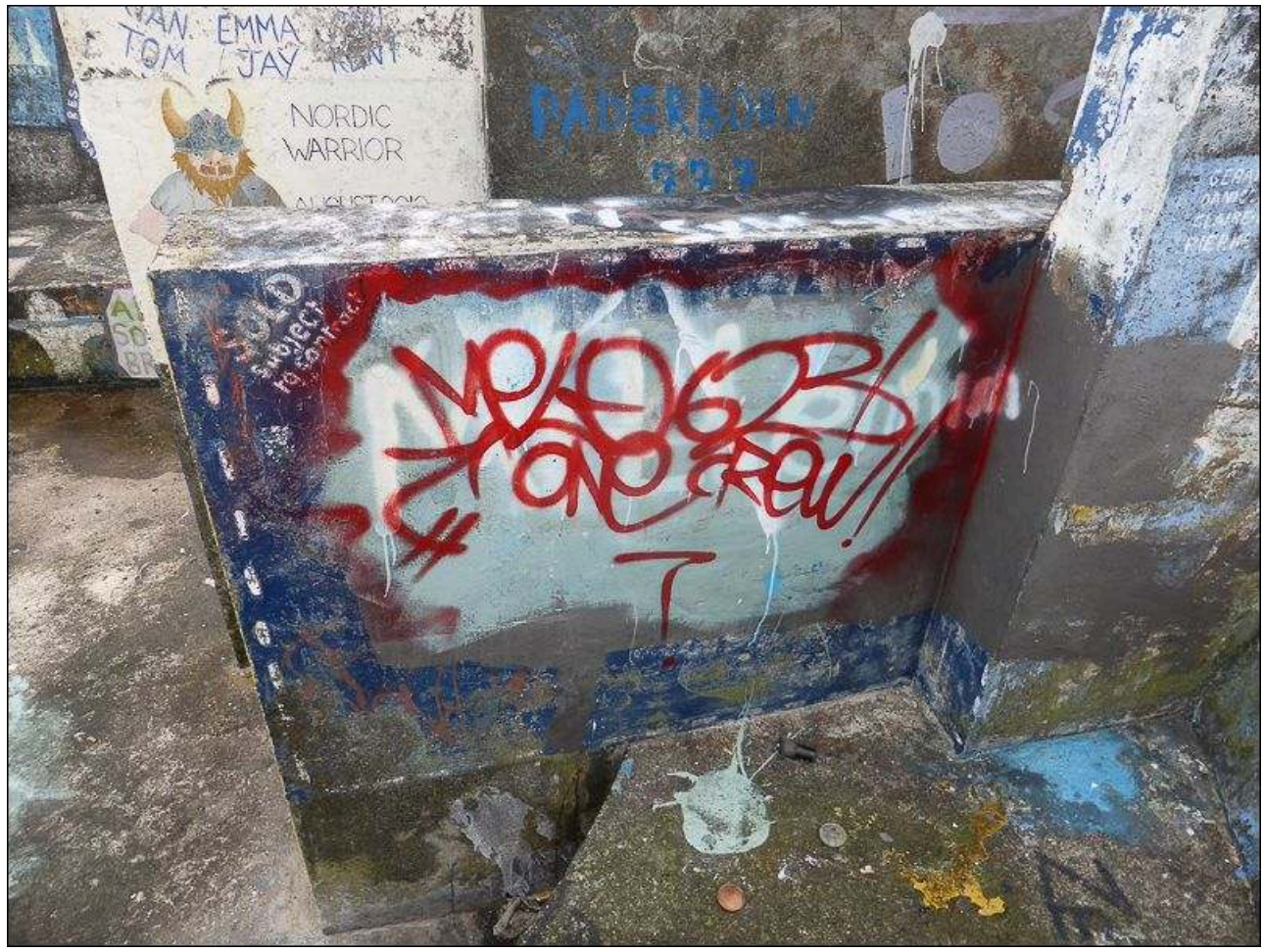

Auteur : L. Marrou, 2014 
Illustration 25 - Peinture façon « lettrage » sur le même parapet : « Tuxo », datant de 2016

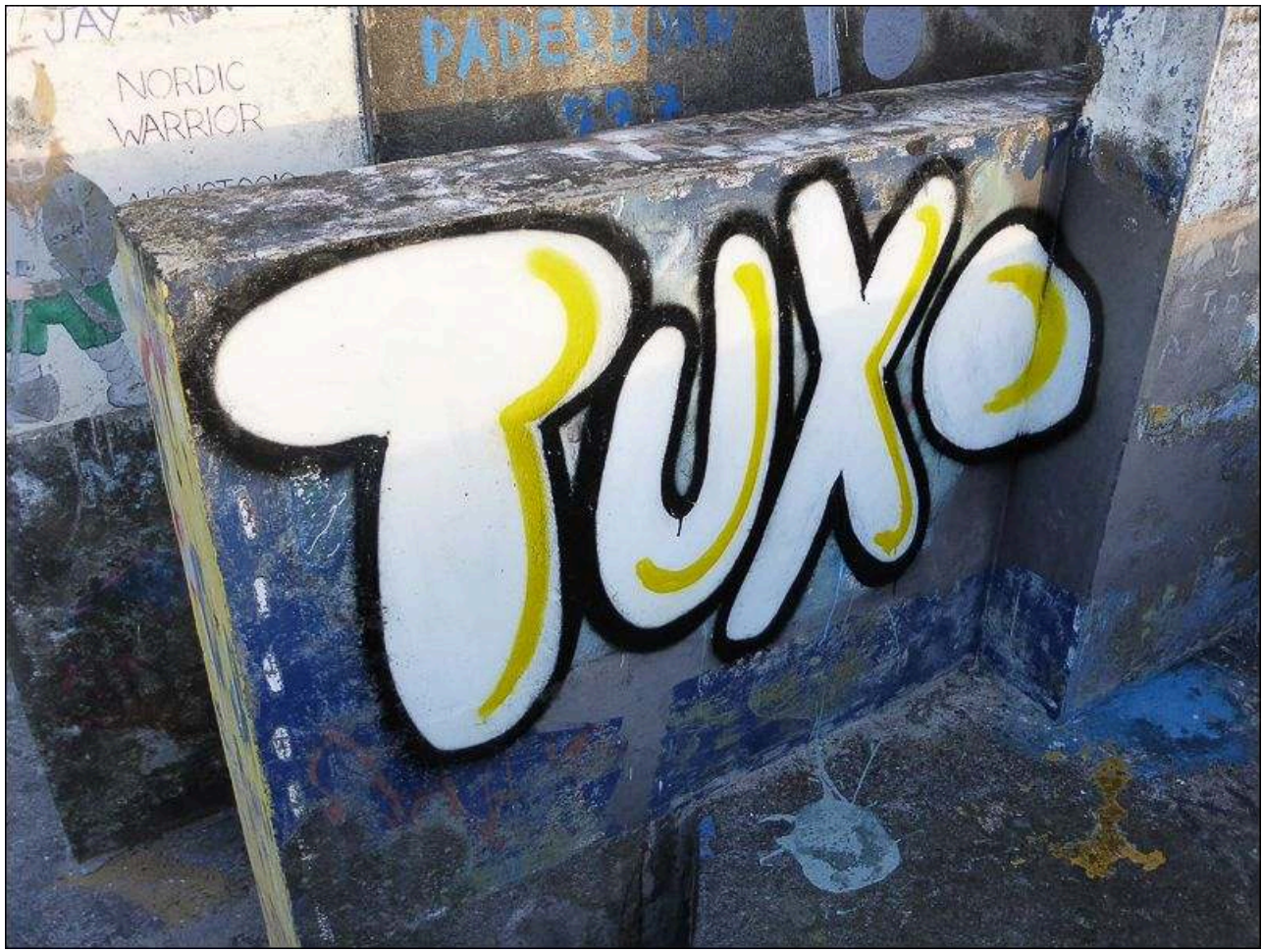

Auteur : L. Marrou, 2016

Les peintures de la marina d'Horta sont une forme originale parmi les expressions du street art littoralo-maritime qui se développent rapidement depuis le début du $\mathrm{XXI}^{\mathrm{e}}$ siècle. Longtemps ce sont les blockhaus de la seconde guerre mondiale qui ont servi d'exutoire à l'inspiration créatrice. Il est désormais fréquent de pouvoir admirer des dessins éphémères sur plages. La réalisation de ses grandes fresques, souvent géométriques, qui durent le temps d'une marée, a acquis une dimension artistique certaine. Elles font ainsi flores sur les côtes atlantiques françaises ${ }^{11}$ et sont mises en valeur par l'utilisation de drones permettant de les découvrir vues du ciel. Les artistes du râteau sur sable utilisent toutes les avancées de la visualisation contemporaine en jouant par exemple de la 3D. Les réalisations, en Océanie, d'un collectif animé par des artistes français (3DSDart pour 3D Sand Drawings) en témoignent ${ }^{12}$.

Sur l'île de Faial, les peintures de la marina d'Horta sont, elles, un chapitre supplémentaire dans une histoire urbaine où la bigarrure côtoie l'éclectisme depuis plus d'un siècle. La petite ville açorienne recèle ainsi des trésors de l'architecture Art Nouveau qu'elle doit à la présence des ingénieurs européens et américains des câbles transatlantiques ayant fait la fortune de la ville à la fin du XIX ${ }^{e}$ siècle et au début du XX siècle. Le patrimoine est là, universel. Les câbles rouillent, les peintures s'effacent. Seuls l'art et l'océan restent. 


\section{BIBLIOGRAPHIE}

Barreira C. G., 1995. Um olhar sobre a cidade da Horta. Do passado ao presente. Roteiros. Horta, Nucleo Cultural da Horta, 148 p.

Blanchard S., 2017. Street art, rénovation urbaine et gentrification dans le Nord-Est parisien : entre marketing urbain et gender mainstreaming. Urbanités [En ligne], 9. http://www.revueurbanites.fr/9-street-art-renovation-urbaine-et-gentrification-dans-le-nord-est-parisien-entremarketing-urbain-et-gender-mainstreaming/)

Bottani E., 2016. Du tag au street art, quand l'art urbain devient un outil de requalification urbaine : une approche comparée des villes de Marseille et Montréal. [En ligne] Mémoire de master 2, Aix-Marseille Université, 168 p. https://dumas.ccsd.cnrs.fr/dumas-01488325/document)

Catz J., 2013. Street art, mode d'emploi. Paris, Flammarion, 255 p.

Demarthon B., 2003. Ébauche d'une géographie de la plaisance aux Açores. Étude et impacts du nautisme sur le territoire açoréen. Document disponible à la Bibliothèque Universitaire de La Rochelle, 201 p.

Dogheria D., 2016. Street art-Histoire, techniques et artistes. Paris, Ed. Place des Victoires, 240 p.

Fedel A., 2013. Le street art à l'heure de son institutionnalisation. Rapport de stage " Forum Avignon » [En ligne], 14 p. https://www.forum-avignon.org/sites/default/files/editeur/

4_Street_art_FEDEL.pdf

Fernandes J. M., 1996. Cidades e casas de Macaronésia. Porto, FAUP, 420 p.

Landes O., 2015. Street art et projet urbain, une mise en valeur dans la ville en transition. Cahiers de Narratologie-Analyse et théorie narratives [En ligne], 29. https://narratologie.revues.org/pdf/ 7401

Marrou L., 2018 (à paraître). Le marin est muet, c'est le quai qui parle. In de F. Taliano-Des Garets (dir.), Soi, l'autre et l'ailleurs. Actes du colloque International de Bordeaux « Images et imaginaires des villes portuaires de l'Europe atlantique et méditerranéenne ».

Marrou L., 2017. La marina et la ville à Horta (île de Faial-Açores) : l'heure de l'émancipation? In V. Herbert et C. Gibout (dir.), Plaisance \& urbanité. L'intégration des ports dans les villes contemporaines. Lille, Presses Universitaires Septentrion, p. 125-137.

Schacter R., 2014. Atlas du street art et du graffiti. Paris, Flammarion, 400 p.

\section{NOTES}

1. Pier : la jetée en anglais.

2. Visitportugal.com (consulté en décembre 2017).

3. "The Mystery of the Great Wall of Faial », texte de Reese Palley disponible sur le site de l'auteur : www.reesepalley.com/faial.html

4. C'est le terme utilisé par les Portugais.

5. Depuis 2006 nous passons systématiquement à l'automne à Horta pour photographier les représentations de l'année et constituer ainsi une base de données iconographique. Nous avons pu par ailleurs, lors de missions printanières dans l'archipel, nous entretenir avec plusieurs dizaines de marins en train de réaliser leurs peintures. Ces travaux ont fait l'objet de publications que l'on peut retrouver en bibliographie. 
6. Global Positioning System.

7. Automatic Identification System.

8. Voir notre communication: «Le marin est muet, c'est le quai qui parle " dans le colloque international de Bordeaux (2015) «Soi, l'autre et l'ailleurs» sur les «Images et imaginaires des villes portuaires de l'Europe atlantique et méditerranéenne », organisé par F. Taliano-Des Garets. 9. www.urbacolors.com/en/map (une œuvre localisée à Ponta Delgada)

10. Le site de l'artiste: www.morganmurals.com et la présentation du projet: https:// www.morganmurals.com/blog/birds-flowers-and-karma-dreams-do-come-true

11. Le site https://www.passion-aquitaine.fr/beach-art-royan/ en donne un aperçu précis.

12. Le site http://www.designfather.com/sand-art-by-3dsd/ en est un bon témoignage.

\section{AUTEUR}

\section{LOUIS MARROU}

Louis Marrou, lmarrou@univ-lr.fr, enseigne la géographie, à temps partiel choisi, à l'Université de La Rochelle ((UMR 7266 LIENSs). Il travaille sur le fonctionnement des archipels atlantiques et la fréquentation des espaces maritimes. Il explore, avec des médecins de l'INSERM travaillant sur la mémoire et le sommeil, une nouvelle thématique de recherche sur la perception de l'espace et des paysages dans les souvenirs de rêves. Il a récemment publié :

- Marrou L., Arnulf I., 2018. Dreams of a geographer: A long dream and waking life series of geographic locations. International Journal of Dream Research, Vol. 11, n 1, p. 13-20. https:// journals.ub.uni-heidelberg.de/index.php/IJoDR/article/viewFile/40949/pdf_1

- Marrou L., 2017. L'Océan mondial n'est pas un aquarium ! Interactions animaux/Activités humaines. In Historiens \& Géographes, Dossier territoires humains, mondes animaux, $\mathrm{n}^{\circ} 439$, p. 71-74 + cartes).

- Marrou L., 2016. Insularité et dépeuplement : le cas de l'île de Flores aux Açores (Portugal). Espace populations sociétés [En ligne], 2015/3-2016/. http://eps.revues.org/6132 